\title{
Imaging Radiation-Induced Normal Tissue Injury
}

\author{
Mike E. Robbins ${ }^{a, c, 1}$, Judy K. Brunso-Bechtold ${ }^{b, c}$, Ann M. Peiffer ${ }^{a, c}$, Christina I. Tsien ${ }^{d}$, \\ Janet E. Bailey ${ }^{\mathrm{e}}$, and Lawrence B. Marks ${ }^{\mathrm{e}}$ \\ aDepartments of Radiation Oncology, Wake Forest University School of Medicine, Winston- \\ Salem, North Carolina \\ bNeurobiology \& Anatomy, Wake Forest University School of Medicine, Winston-Salem, North \\ Carolina \\ 'Brain Tumor Center of Excellence, Wake Forest University School of Medicine, Winston-Salem, \\ North Carolina \\ dDepartment of Radiation Oncology, University of Michigan, Ann Arbor, Michigan \\ eDepartment of Radiation Oncology, University of North Carolina Chapel Hill, Chapel Hill, North \\ Carolina
}

\section{Abstract}

Technological developments in radiation therapy and other cancer therapies have led to a progressive increase in five-year survival rates over the last few decades. Although acute effects have been largely minimized by both technical advances and medical interventions, late effects remain a concern. Indeed, the need to identify those individuals who will develop radiationinduced late effects, and to develop interventions to prevent or ameliorate these late effects is a critical area of radiobiology research. In the last two decades, preclinical studies have clearly established that late radiation injury can be prevented/ameliorated by pharmacological therapies aimed at modulating the cascade of events leading to the clinical expression of radiation-induced late effects. These insights have been accompanied by significant technological advances in imaging that are moving radiation oncology and normal tissue radiobiology from disciplines driven by anatomy and macrostructure to ones in which important quantitative functional, microstructural, and metabolic data can be noninvasively and serially determined. In the current article, we review use of positron emission tomography (PET), single photon emission tomography (SPECT), magnetic resonance (MR) imaging and MR spectroscopy to generate pathophysiological and functional data in the central nervous system, lung, and heart that offer the promise of, (1) identifying individuals who are at risk of developing radiation-induced late effects, and (2) monitoring the efficacy of interventions to prevent/ameliorate them.

\section{INTRODUCTION}

Radiation therapy (RT) remains one of the major treatment options for cancer patients; approximately $60 \%$ of all newly-diagnosed patients will receive RT sometime during the course of their treatment (1). RT represents a targeted, noninvasive, and potentially organpreserving therapy. However, the total dose that safely can be administered to a tumor is limited by the risk of both acute- and late-radiation-induced injury to those normal tissues unavoidably included in the treatment volume. Ongoing advancements in RT and other

(C2012 by Radiation Research Society. All rights of reproduction in any form reserved.

${ }^{1}$ Address for correspondence: Room 412C NRC, Department of Radiation Oncology, Wake Forest University School of Medicine, Medical Center Blvd., Winston-Salem, NC 27157; mrobbins@wfubmc.edu. . 
cancer therapies have resulted in a progressive increase in five-year survival rates over the last 50 years; $68 \%$ of adult and $81 \%$ of pediatric cancer patients now survive beyond five years (2). In general, acute effects have been minimized by both technical advances and medical interventions. However, for the $\sim 12$ million long-term survivors, there are no proven interventions to prevent or mitigate radiation-induced late effects. Thus, the need to, (1) identify those individuals who will develop radiation-induced late effects, and (2) develop interventions to prevent or mitigate these radiation-induced late effects is currently recognized as a critical area of radiobiology research (3).

Preclinical studies carried out over the last two decades clearly demonstrate that radiationinduced late effects arise not simply from mitotic cell death of specific target cell clonogens, but more importantly, from complex and dynamic interactions between multiple cell types within an organ (4-7). Thus, normal cells are active participants in the response to injury that is hypothesized to initiate an ongoing, chronic process that leads to progressive damage. Although the exact specific pathogenic mechanisms remain to be determined, late radiation injury can be prevented/ameliorated by pharmacological therapies focused on modulating steps in the cascade of events leading to the clinical expression of radiation-induced late effects (8).

These recent advances in our understanding of how radiation-induced late effects develop and how they can be modulated have been accompanied by significant technological advances in imaging that offer the promise of identifying individuals who are at risk for developing radiation-induced late effects. Thus, normal tissue radiobiology is moving from a discipline utilizing conventional histologic analysis of fixed tissues from many experimental groups with large numbers of animals collected over many time points, to one in which noninvasive in vivo imaging enables serial assessment of pathophysiological and functional processes in fewer groups with smaller numbers of animals, where each animal serves as its own control $(9,10)$. This process has also been facilitated by advances in clinical imaging that have shifted radiation oncology from a discipline driven by anatomy and structure to one in which important quantitative functional data can be determined $(11,12)$.

$\left[{ }^{18} \mathrm{~F}\right]$ fluorodeoxyglucose (FDG) positron emission tomography (PET) imaging provides functional data on normal tissue metabolic activity, while other radiotracers can image physiologic parameters such as angiogenesis (13), hypoxia (14), cardiac function (15), and brain function (16). Single photon emission computed tomography (SPECT) has been used to measure perfusion (17). Magnetic resonance imaging (MRI) has become increasingly important with its ability to assess functional metrics including regional perfusion (18), lung ventilation (19), and brain structure, as well as function (20, 21); In addition, metabolic states can now be assessed with MR spectroscopy (MRS) (22). More recently, multimodality imaging with PET/CT and SPECT/CT has become commonplace in radiation oncology, and ongoing research is investigating combining PET or SPECT with MRI (23). In the current article, we review the use of pathophysiologic and functional imaging that offers the promise of, (1) identifying individuals who are at risk for developing radiationinduced late effects and (2) monitoring the efficacy of interventions to prevent or mitigate them. Our focus will be on central nervous system (CNS), lung, and cardiac normal tissues, and will include discussions of opportunities for future research in this field.

\section{CNS Injury}

Based on the time of clinical expression, radiation-induced brain injury is described in terms of acute, early-delayed, and late-delayed reactions (5). Acute injury (acute radiation encephalopathy), expressed in days to weeks after irradiation, is rare under current RT regimens. Early delayed injury occurs from 1-6 months postirradiation and can involve transient demyelination with somnolence, which is mainly seen in children but also can 
affect adult patients in the first 2 months after RT. While these early injuries can result in severe reactions, they usually resolve within 1-3 months, either spontaneously or following treatment with corticosteroids and their severity is not necessarily predictive of the more devastating late effects. Late delayed effects, characterized histopathologically by demyelination, vascular abnormalities and, ultimately, white matter necrosis (24), are observed $>6$ months postirradiation after relatively high doses (>60 Gy) of fractionated RT $(5,25)$.

There is a growing awareness of intellectual deterioration in patients receiving brain irradiation (26) that can occur with relatively low total doses and in the absence of apparent structural lesions. Although diverse in character, this often includes hippocampal-dependent functions including learning, memory, and spatial information processing. Cognitive impairment, including dementia, induced by partial- or whole-brain irradiation (WBI) is reported to occur in up to $50 \%$ of adult patients who are long-term ( $>6$ months postirradiation) survivors (27-29). The resultant impact on quality of life (QOL) has become an extremely important concern for long-term survivors, particularly for the adult survivors of childhood cancer who present with an extraordinarily high incidence of late, and often permanent, complications, including cognitive sequelae, arising from combined RT and chemotherapy (30-33).

Currently there are no validated diagnostic procedures for determining who will or will not develop radiation-induced brain injury, including cognitive impairment, or who will/will not respond favorably to therapies aimed at preventing or ameliorating these deficits. Radiationinduced late effects occur within the closed cranial cavity, and thus, noninvasive techniques offer the opportunity to study this significant side effect of brain tumor RT. Early studies used CT, histology and neurological changes to investigate radiation-induced late effects in the dog brain after hemibrain irradiation with large single doses (34). MRI use in the clinic has been translated into experimental studies of the effects of large single doses on the rat (35-37), cat $(38,39), \operatorname{dog}(40,41)$, and pig (42) brain as well as fractionated irradiation of the mouse brain (43). CT and MRI have enabled serial evaluation of animals over a prolonged period and identified radiation-induced brain injury as either a white matter hypodensity on $\mathrm{CT}$ or an increased $\mathrm{T} 2$ signal abnormality on MRI.

A limitation of these studies is that the primary morbidity associated with modern brain RT techniques is functional, rather than structural. For brain tumor patients, radiation-induced cognitive impairment represents a major morbidity than can markedly impact their QOL.

Progressive cognitive impairment can occur without any MRI evidence of white matter necrosis (44). Similarly, fractionated (f)WBI of the rat brain leads to progressive cognitive impairment in the absence of demyelination, gliosis, and white matter necrosis (45). Cognitive impairment can also occur with no change in the number of oligodendrocytes and myelinated axons, or thickness of myelin sheaths 1 year following fWBI (46). These findings suggest that more sensitive imaging techniques that focus on microstructure [e.g., diffusion tensor imaging (DTI) (21) and metabolic changes (MRS) (22)] might detect the neurobiological changes that lead to altered neural processing following fWBI.

\section{MRI}

MRI utilizes magnetic fields to generate tissue images by exciting protons and monitoring them as they relax. In addition to standard structural images that look at gross anatomy, DTI is capable of assessing tissue microstructure by measuring the diffusion or motion of water molecules along multiple tensors within each image voxel. DTI provides a mechanism to identify microstructural abnormalities due to radiation injury well before macrostructural changes are visible $(47,48)$. A minimum of six tensors need to be acquired for calculating the DTI indexes. Water diffusion along each tensor is measured for each voxel and by 
averaging the diffusion in all directions, the mean diffusivity, or trace, is calculated. Areas with little structure allow water to freely diffuse and will have higher mean diffusivity values than areas with more structure, such as the white matter. The Fractional Anisotropy (FA) is determined from calculating the first, second and third eigenvalues $(\lambda 1, \lambda 2$ and $\lambda 3)$ of the tensor field, which describes whether diffusion is either elliptical or spherical. When the voxel is placed within highly-structured regions such as white matter bundles, water diffusion is restricted or anisotropic, and FA is near 1 (Fig. 1A, aqua arrow head within the anterior commissure). High FA values indicate that $\lambda 1$ is significantly greater than the perpendicular eigenvalues $\lambda 2$ and $\lambda 3$, which creates an elliptical or tube-shaped diffusion pattern. When the voxel is placed in less structured regions, such as the cerebral spinal fluid (Fig. 1A, yellow arrow head), or demyelinated white matter, water diffusion is less restricted or isotropic, and FA is closer to 0 . Lower FA values indicate a smaller difference between $\lambda 1$ and the perpendicular eigenvalues $\lambda 2$ and $\lambda 3$, which creates a more spherical diffusion pattern.

Parallel diffusivity $\left(\lambda_{\|}\right)$refers to the first eigenvalue and represents the greatest amount of diffusion in one direction, which is typically along the axons of white matter tracts. DTI processing frequently color-codes the directions of diffusion to allow greater separation of different anatomical tracts and interpretation of the direction of information flow (Fig. 1B); therefore it actually shows the movement of water in 3-dimensional (3D) space.

Perpendicular diffusivity $\left(\lambda_{\perp}\right)$ refers to diffusion along the second and third eigenvalues ( $\lambda 2$ and $\lambda 3$ ) and is commonly calculated as an average between them. The second eigenvalue is the second highest value of diffusion perpendicular to $\lambda 1$, while $\lambda 3$ is restricted to diffusion perpendicular to both $\lambda 1$ and $\lambda 2$. Quantitative measures obtained from these DTI indices have been interpreted to distinguish between myelin loss and axonal injury. With demyelination, there is a greater increase in perpendicular diffusivity $\left(\lambda_{\perp}\right)$ with little or no change in parallel diffusivity $\left(\lambda_{\|}\right)$, while with axonal injury there is a decrease in $\lambda_{\|}$with little or no change in $\lambda_{\perp}(49,50)$. While, these interpretations are limited to white matter tracts; differences in DTI parameters are also found in cortical areas and represent alterations in how water diffuses through the extracellular matrix, synaptic field, and/or small myelinated/unmyelinated axons. These DTI indices can be compared on a voxel-byvoxel basis throughout the 3D brain space, or on a region-of-interest (ROI) basis within specific anatomical regions (Fig. 1C).

\section{DTI as an Imaging Biomarker of Late CNS Toxicity}

DTI has been used to assess early white matter injury in both pediatric and adult patients treated with partial- and WBI (51-55). A recent, prospective DTI study was undertaken at the University of Michigan in which patients with high-grade gliomas $(n=19)$, low-grade gliomas $(n=3)$, and benign tumors $(n=3)$ received partial brain irradiation; DTI was performed before, during, and after irradiation (51). Analyses revealed progressive changes secondary to RT in the genu (anterior portion) and splenium (posterior portion) of the corpus callosum. During the first 3 months post-RT, dose-dependent demyelination (i.e., increased $\lambda_{\perp}>\lambda_{\|}$) was noted predominantly in regions receiving high doses of RT. However, 6 months following the start of RT, the diffuse demyelination was no longer limited to the high RT dose regions. The latency in diffuse demyelination suggests an opportunity for early intervention to avoid permanent late radiation-induced white matter damage (51). This study confirms that DTI indices have the potential to detect changes in the normal appearing white matter (NAWM) of CNS patients receiving partial brain irradiation.

Similar preclinical data are available for example, DTI of the rat brain 1 year after right hemibrain irradiation with 28 Gy of $6 \mathrm{MV}$ photons revealed a significantly greater decrease in functional ainisotropy (FA) in the ipsilateral fimbria of the hippocampus than in the external capsule, indicating selective vulnerability of the fimbria to irradiation (48). 
Longitudinal evaluation of white matter injury in the rat brain imaged 2 to 48 weeks after 25 and $30 \mathrm{~Gy}$ hemibrain irradiation revealed a progressive reduction in FA, which was driven by a reduction in $\lambda_{\|}$from 4 to 40 weeks postirradiation, and an increase in $\lambda_{\perp}$ with a return to baseline for $\lambda_{\|}$at 48 weeks postirradiation (56). Moreover, changes in $\lambda_{\|}$correlated with reactive gliosis, while $\lambda_{\perp}$ correlated with demyelination. In middle-aged rats treated with fWBI, DTI performed 1 year postirradiation revealed no apparent changes in FA in heavilymyelinated axons (corpus callosum, cingulum, and deep cortical white matter). However, significant fWBI-induced injury was present in the superficial parietal cortex as indicated by a fWBI-induced decline in FA in the more anterior slices through the parietal cortex (57). These findings suggest that fWBI-induced changes may be more pronounced in the less myelinated/unmyelinated axons, extracellular matrix, or synaptic fields rather than in heavily-myelinated tracts.

Pediatric studies also support the utility of DTI as a clinically-relevant tool for the assessment of treatment-related neurotoxicity, and as a potential adjunct to intelligence quotient (IQ) scores. A cross-sectional DTI study of post-treatment survivors of childhood medulloblastoma and acute lymphoblastic leukemia (ALL) was performed and compared to age-matched controls. Decreases in FA were associated with declines in IQ scores after adjusting for the effects of age, RT dose, and time interval from treatment (52). Significant decreases in FA were noted in the white matter of both frontal and parietal lobes in childhood medulloblastoma survivors compared to controls. Greater declines in FA were noted in frontal compared to parietal lobes for the same RT dose, suggesting increased radiosensitivity of the frontal lobes which are myelinated and develop throughout childhood and adolescence (53). Additionally, late structural abnormalities in normal appearing cerebral white matter were indicated by significantly-reduced FA values in the temporal lobe, hippocampus, and thalamus of adult survivors treated for ALL following WBI compared to age-matched controls (54). Although changes in structural properties of NAWM are noted postirradiation, prospective neurocognitive testing prior to RT is required to correlate these findings with late-delayed radiation-induced cognitive impairment.

Radiation-induced injury to the hippocampus region may be associated with long-term deficits in learning, memory, and executive function. Demyelination or axonal injury within this area could impact the efficiency of communication between the hippocampus and the rest of the cortex, thereby impacting learning and memory. In a preliminary study at the University of Michigan, 12 patients with brain metastases treated with fWBI with RT total doses of 30-37.5 Gy were prospectively assessed with DTI prior to RT, at the end of RT, and one month following RT. Specific ROIs included the parahippocampal cingulum, a prominent white matter fiber tract bundle of the limbic system. A decrease in FA was noted in the parahippocampal cingulum 1 month after completion of fWBI (Fig. 2) (58). More specifically, a significant increase in $\lambda_{\perp}$ without a significant change in $\lambda_{\|}$was noted in this region, suggesting early demyelination of the white matter (Fig. 2D). These results suggest that DTI indices may be a useful noninvasive biomarker to, (1) monitor patients who are treated with hippocampal-sparing WBI regimens, and (2) for predicting cognitive performance following RT (59).

In summary, DTI is able to detect early changes in white matter integrity. These changes in the properties of NAWM may be related to late-delayed cognitive decline. Currently, ongoing studies combining DTI and neurocognitive testing are investigating longer follow-up times (up to 18 months after RT) to determine the predictive power of these MRI biomarkers. By identifying patients with early changes in white matter integrity, it may be possible to predict which patients will have greater inherent radiation sensitivity, so that interventions can begin earlier. 


\section{MR Perfusion Imaging}

Vascular damage may also play a critical role in the development of late radiation-induced injury, including radiation necrosis $(60,61)$. Early histopathologic changes noted in blood vessels following irradiation include vessel dilatation, endothelial cell enlargement, and perivascular astrocyte hypertrophy, which can lead to blood-brain barrier (BBB) disruption, increased permeability, and edema. Acute vascular injury following irradiation potentially can be detected prior to the development of acute demyelination and white matter necrosis $(62,63)$. Dynamic contrast enhanced (DCE) MRI using T1-weighted imaging allows quantitative assessment of vascular permeability by repeatedly imaging brain tissue prior to and following a short bolus injection of an MRI tracer into the blood stream. By tracking the movement of the tracer into the image volume and using compartmental modeling, a transfer constant or $\mathrm{K}^{\text {trans }}$ value for passive leakage of the tracer from the intravascular space to the extravascular space can be calculated (64). Areas with high $\mathrm{K}^{\text {trans }}$ values have a leaky vascular wall that allows movement of the tracer out of intravascular space more readily than from areas with intact vasculature. These functional characteristics of the vascular microenvironment may provide an early indication of radiation-induced changes that correlate with late cognitive impairment.

In a preliminary clinical study, changes in blood plasma volume $\left(\mathrm{V}_{\mathrm{p}}\right)$ and $\mathrm{K}^{\text {trans }}$ were evaluated in normal-appearing cerebral tissue following partial brain irradiation (65). $\mathrm{K}^{\text {trans }}$ was highest during the 6th week of RT and decreased in a dose-dependent manner following the conclusion of therapy; it returned to baseline levels 6 months postirradiation. Increases in $\mathrm{K}^{\text {trans }}$ indicate changes in BBB permeability/perfusion effects which could be related to radiation-induced cell death and apoptosis $(63)$. $\mathrm{V}_{\mathrm{p}}$ however, displayed a dose-dependent response with low fractionated regimens $(<20 \mathrm{~Gy})$ showing no significant increase in $V_{p}$. Higher-dose regimens showed a differential increase in $V_{p}$ during $R T$ with larger doses inducing faster and larger increases. Although $\mathrm{V}_{\mathrm{p}}$ decreased after RT; this decrease was still less than baseline levels 6 months postirradiation. At 6 months postirradiation, vascular microenvironment changes evident during the 3 rd week of RT within left hemisphere frontal and temporal lobes were significantly correlated with declines in verbal learning scores on the Hopkins Verbal Learning Test (HVLT). When the temporal lobe was divided into hippocampal and nonhippocampal ROIs in 12 patients, $\mathrm{V}_{\mathrm{p}}$ at 3 weeks continued to correlate with the HVLT learning scores 6 months postirradiation for both ROIs (65). Validation studies of these initial findings are currently on-going. However, they suggest that sparing of the hippocampus alone may not be sufficient to protect memory function following WBI.

\section{MR Proton Spectroscopy}

Proton MRS is a noninvasive technique to, (1) interrogate metabolic distributions in the brain $(66,67),(2)$ differentiate radiation necrosis from brain tumor progression $(68,69)$, and (3) serve as an indicator of neurotoxicity following experimental $(48,70)$ and clinical brain irradiation (71-76). Metabolites detected in brain tissue include choline-containing compounds, creatine, glutamate, lactate, $N$-acetylaspartate (NAA), myoinositol (mI) and taurine. The concentration of each of these metabolites can be mapped from $2 \mathrm{D}$ or $3 \mathrm{D}$ spectroscopic images having a voxel size of $0.7-1 \mathrm{~cm}^{3}$. The metabolite, $N$-acetylaspartate (NAA) is predominantly a neuronal marker, and decreases are associated with neuronal damage and dysfunction secondary to radiation. Choline is associated with cell membrane synthesis and/or increased metabolic turnover; it is elevated in both tumors and inflammatory processes. Creatine is a marker of energy metabolism with relatively constant concentrations throughout the brain (77), while $\mathrm{mI}$ is a glial cell marker and has been used as an indicator of myelin breakdown (78). 
Very little preclinical data are available on MRS detection of metabolite changes in the normal brain following irradiation. Using a 4.7T MR spectrometer and a voxel size of approximately $30 \mathrm{~mm}^{3}$, Herynek et al. (70) observed decreases in creatine and NAA 8 and 12 months after bilateral Gamma Knife irradiation of the hippocampus of young adult male rats with $35 \mathrm{~Gy}$, a dose that led to severe functional and structural impairment. Chan et al. (48) used a 7T MR spectrometer and a voxel size of $64 \mathrm{~mm}^{3}$ to determine significant increases in choline, glutamate, lactate, and taurine levels 12 months after right hemibrain irradiation of young adult male rats with a single dose of $28 \mathrm{~Gy}$ of $6 \mathrm{MV}$ photons. These changes in white matter were confirmed histologically. Using a similar 7T spectrometer and a larger voxel size of $125 \mathrm{~mm}^{3}$ (Fig. 3), Atwood et al. (79) reported a potential relationship between radiation-induced changes in rat brain metabolites and cognitive impairment 52 weeks after fWBI. MRS spectra obtained 12 weeks after 40 Gy fWBI failed to show any significant differences in brain metabolites or cognitive impairment between the fWBI and sham-irradiated rats. In contrast, analysis of MR spectra obtained 52 weeks postirradiation revealed significant increases in the NAA/total creatine + phosphocreatine $(\mathrm{tCr})$ and the glutamate + glutamine/tCr ratios, as well as a decrease in the $\mathrm{mI} / \mathrm{tCr}$ ratio compared with age-matched sham-irradiated controls. Assessment of cognitive function in these rats 54 weeks postirradiation revealed a significant reduction in the irradiated animals. Thus, these findings suggested that MRS may be a sensitive tool to detect changes in radiation-induced brain metabolites that may be associated with radiation-induced cognitive impairment (79). However, more recent studies using this fWBI model indicated that these changes in rat brain metabolites occur after the expression of radiation-induced cognitive impairment, and do not appear to cause or predict the onset of radiation-induced cognitive impairment (45).

MRS has also been used to assess metabolite changes in NAWM following RT (71-75). In a cross-sectional study of ALL survivors following intrathecal methotrexate and prophylactic cranial irradiation, MRS detected decreasing NAA/Cr and $\mathrm{Cho} / \mathrm{Cr}$ ratios with increasing time after RT ranging from 5.6 to 19 years, suggesting long-term brain injury secondary to decreases in NAA and Cho (76).

In an initial prospective study of 11 adult patients with low-grade gliomas or benign tumors, such as pituitary adenomas and meningiomas treated with partial brain irradiation, MRS demonstrated significant alterations in brain metabolites in normal appearing brain parenchyma, both during irradiation and over a 6-month period post-RT. Similar to the previous study, decreases were also noted in both the NAA/Cr and Cho/Cr ratios starting 3 weeks following RT that persisted for up to 6 months (71).

Several small studies have demonstrated significant alterations in brain metabolites in normal appearing brain parenchyma following RT (72-75). Transient metabolic changes were noted in glioma patients 4 months following RT with increases in the Cho/NAA and Cr/NAA ratios that appeared to resolve over time (72). In a prospective study of high-grade glioma patients, similar findings were noted in normal appearing brain parenchyma following RT. Transient increases in the Cho/NAA ratios were noted 2 months following RT in NAWM regions receiving low, moderate, and high RT doses; recovery was dosedependent (73). Similarly, in a cross-sectional adult glioma study, metabolite changes were much more pronounced in radiation-induced hyperintensity areas (RIHA) compared to NAWM. In RIHA regions, a decrease in both NAA and Cho was suggestive of myelin damage and axonal necrosis; in NAWM regions, a decrease in Cho was suggestive of membrane damage in myelin-producing oligodendrocytes that accompanies impaired tissue perfusion due to endothelial radiation effects (74).

In summary, MRS is a noninvasive imaging technique that can monitor radiation-induced changes in brain metabolites. Clinically, there are significant technical challenges that 
remain in reproducibly measuring chemical metabolites near brain tumor regions. There may be signal contamination from the ROI's proximity to the ventricles, scalp and surgical clips. Normal tissues adjacent to the tumor bed may also affect local-field homogeneity and data quality (77). Ongoing studies involve the temporal dynamics of radiation-induced injury and its associated metabolite changes as well as the relationship between the detection of early tissue damage and the development of late symptomatic cognitive impairment.

\section{PET}

The effect of fWBI on brain function has recently been investigated in nonhuman primates (NHPs) using FDG-PET imaging by determining local rates of glucose metabolism/uptake $\left(\mathrm{CMR}_{\mathrm{glc}}\right)$ during a Delayed-Match-to-Sample (DMS) cognitive function task (80). The $\mathrm{CMR}_{\mathrm{glc}}$ in a brain region is an indicator of neurosynaptic activity in that region, and has become a standard technique in dementia research (81). PET scans performed 1 week prior to fWBI revealed that the brain regions activated during the DMS task were the dorsal prefrontal cortex (DPFC), the medial temporal lobe (MTL), the parietal cortex (precuneus), and dorsal striatum (DStr); areas repeatedly implicated in human and NHP cognitive function $(82,83)$. As anticipated, PET scans performed 9 months after fWBI, when cognitive function was significantly impaired, revealed reduced glucose metabolism in the cuneate and DPFC regions compared to pre-fWBI values (80). In contrast, glucose metabolism in the cerebellum and thalamus, regions that were not engaged during the DMS task prior to fWBI, was increased, indicating a potential imbalance in frontal subcortical circuits (Fig. 4) (84). Indeed, decreased capacity to perform higher-order executive functions has been shown to involve the DFPC, hippocampus, cuneate, and motor areas in cancer survivors following fWBI (44).

\section{Lung Injury}

Symptomatic pulmonary injury is one of the most common side effects in patients undergoing thoracic RT (85). Noninvasive radiologic imaging techniques can be used to assess regional damage, reduced function, and potentially to predict clinically-relevant outcomes. However, radiologic evidence of pulmonary injury is not always accompanied by clinical symptoms. For example, in lung cancer patients who receive RT, 50\% to $100 \%$ will develop radiologic evidence of lung injury, while only $5 \%$ to $35 \%$ develop clinical symptoms (85-87). Similarly, for breast cancer patients who receive RT, up to $63 \%$ develop radiologic evidence of lung injury, while 34\% or fewer develop clinical symptoms (88-93).

The likelihood of clinical pulmonary injury is related to RT dose, irradiated volume, and fractionation schedule. Systemic therapies (e.g., chemotherapy, hormone therapy, or immunotherapy) may affect the incidence and severity of RT-induced injuries, as may patient-specific factors, such as pre-treatment pulmonary function and a history of smoking (86, 94-98).

Pulmonary injuries are typically divided into early- (or acute)-phase injuries and late- phase injuries. Radiation pneumonitis, an early-phase complication usually developing within 6 months of RT, is commonly characterized by cough and dyspnea, and typically responds well to steroids. It occasionally resolves without treatment $(92,99,100)$. Fibrotic injury is a late complication, usually presenting at least 6 months post-RT and, if symptomatic, can involve progressive dyspnea and possible mortality $(86,97)$.

Radiologic evidence of radiation pneumonitis can be variable in appearance with increased density associated with inflammation (acute) (101), or increased density accompanied by contraction, and pleural thickening (late) (102). The frequency of detecting radiologic abnormalities depends on the sensitivity of the radiographic assessment. For example, 
computed tomography $(\mathrm{CT})$ is more sensitive than chest radiography because it provides 3D visualization of the lung (102).

\section{CT and SPECT}

Preclinical studies using mouse and rat models have demonstrated that serial CT imaging can be used to demonstrate both dose-dependent increases in lung density following singledose irradiation $(103,104)$, and strain-specific differences in acute- and/or late-radiation injury (105). More recently, a methodology for quantitatively measuring structural regional changes in homogeneously-irradiated rat lungs has been developed (106). Lung function has been assessed using radionuclide perfusion assays. And, it was shown that hemithoracic irradiation of the rat lung leads to decreased arterial perfusion as assessed using technecium-99m-labeled macroaggregated albumin that is evident within 4 to 6 weeks of irradiation with a single dose of 25 (107) or $28 \mathrm{~Gy}(108)$.

Noninvasive imaging techniques for assessing RT-induced lung injury have been previously described in detail $(94,102)$. CT scans provide lung tissue density information that can be associated with 3D RT dose-distribution maps. SPECT imaging is a sensitive means of assessing regional lung function such as perfusion and ventilation. RT affects both ventilation and perfusion, which is best demonstrated by the work of researchers at the Netherlands Cancer Institute (NKI; 109). Their data, and that of several others, suggest that perfusion is a more sensitive measure of normal tissue injury than is ventilation. Physiologically, the lung is better able to reduce blood flow to unventilated areas (via capillary/vascular constriction) than to reduce ventilation to unperfused areas (bronchi are less able to be constricted). Therefore, reductions in ventilation will generally also cause perfusion reductions, but the reverse is less-often true. Thus, perfusion is a more sensitive metric for assessing RT-induced lung injury.

For both CT and SPECT, pre- and post-RT images can be compared to the 3D dose distribution to study the dose-dependent nature of RT-induced regional lung injury. Perfusion defects are more common than ventilation defects, and both are more common than changes in CT (94). Investigators from Duke University, the NKI, and the Princess Margaret Hospital (PMH) have reported prospective data relating lung RT dose to CTdefined lung injury $(100,109,110)$. In a study of 25 patients irradiated for malignant lymphoma, Boersma et al. at the NKI observed dose-dependent increases in CT density 3 to 4 months post-RT (109). Mah et al. at the PMH studied changes in CT density up to 6 months following lung irradiation for 54 patients; dose-dependent increases in the frequency of CT-defined lung injury were observed (110). At Duke, Levinson et al. studied changes in local CT density for 13 patients with lung cancer (100). Significant increases in CT density were observed for regions of lung receiving >60 Gy; smaller increases were observed for regions receiving smaller doses. The pre- and post-RT CT images, for a typical irradiated lung cancer patient, are shown in Fig. 5A and B. Increased density is seen on the post-RT CT image (indicated by an arrow in Fig. 5B) and is associated with inflammation.

Similar to CT images, pre- and post-RT SPECT images can be compared to the 3D dose distribution to study the dose-dependent nature of regional RT-induced lung injury. Pre- and post-RT SPECT perfusion images, including the isodose distributions, for an irradiated lung cancer patient are shown in Fig. 6A and B; the dose-response curve for RT-induced reductions in regional perfusion are shown in Fig. 6C. Using 3D image-fusion techniques, investigators at Duke and NKI have related changes in pre- and post-RT CT density, SPECT ventilation, and SPECT perfusion to the 3D regional dose distribution (Fig. 7) (100, 109, 111-114). 
Several investigators have established a connection between the extent of radiologic evidence of pulmonary injury and clinically-relevant symptoms $(110,115,116)$. Fan et al. at Duke, and Theuws et al. at NKI, showed a correlation between reductions in pulmonary function tests (PFTs) and integrated changes in regional perfusion, i.e., the integrated response (116-118). Although statistically significant, the relatively weak correlation between reduced PFT performance and integrated response suggests the existence of additional factors to explain post-RT changes in PFT. A stronger association between pulmonary symptoms (Grade 2 ) and the estimated sum of regional functional changes has been shown by Gopal et al. (119).

Recent reports have focused on radiation-induced lung injury after stereotactic radiosurgery. In a study of 31 patients receiving stereotactic radiosurgery for primary or metastatic lung lesions, Aoki et al. noted asymptomatic increases in CT density 2 to 6 months post-RT, and later fibrotic reactions at 6 and 15 months post-RT (120). While all 31 patients developed radiographic changes, no patients developed severe symptoms (e.g., Grade $\geq 2$ or requiring steroids). When follow-up CTs were compared to the dose distribution on the treatment planning CT, investigators observed that the minimal dose for the development of CTdefined changes in lung tissue density ranged from 16 to $36 \mathrm{~Gy}$.

\section{MRI}

Contrast-enhanced MRI may also be used to describe perfusion characteristics of various phases of RT-induced lung injury. Japanese studies suggest that MRI can also detect radiation-induced lung injury in animal models. Shioya et al. used MR techniques to determine the extent of radiation-induced lung tissue damage in rats within 2 weeks of a 20 Gy single fraction to the hemithorax. They found that MRI was more sensitive than conventional imaging techniques for detecting early effects on normal tissue (121). Ogaswara et al. also suggested that contrast-enhanced perfusion MRI may be helpful in differentiating acute pneumonitis from late fibrosis in dogs (122).

Similar results using contrast-enhanced perfusion MRI for distinguishing acute pneumonitis from late fibrosis have been reported in the clinical setting $(122,123)$. A recent study by Muryama et al. suggested that pulmonary hypertension, detected by velocity-encoded cine (VEC) MRI, may be used as a predictor of radiation pneumonitis (124). MRI has also been suggested to be potentially useful to detect differences in tumor response during treatment, with the potential to guide adaptive changes in treatment plans (123).

\section{PET}

FDG-PET imaging provides regional functional information that has potential for assessing RT-induced lung injury. A recent study by Hart et al. at MD Anderson Cancer Center, noted dose-dependent increases in regional FDG-PET activity in 101 esophageal cancer patients assessed 3 to 12 weeks post-RT (125). Further, the severity of the regional inflammatory changes appeared to be significantly correlated with the probability of symptoms. Data from several studies using SPECT, CT, MRI, and PET to detect changes in the lung following thoracic RT are summarized in Table 1. In some of the studies, the rate of symptomatic shortness of breath is also noted. These data are included in the table and illustrate that imaging is more sensitive than clinical symptoms as a marker of RT-induced lung injury.

In summary, several investigators have used a variety of imaging tools to study RT-induced regional injury/changes. For some, there is a reasonable dose-response relationship. The association between the extent/severity of regional imaging changes and changes in global function is less well-defined. Additional work is needed to better clarify the relationship between changes in regional imaging and changes in global function. 


\section{HEART INJURY}

RT to the thorax may induce both early and late cardiac effects if portions of the heart are included in the radiation field. Patients with breast cancer and Hodgkin's disease are particularly at risk for developing late myocardial damage, due to their longevity and possibly to the frequent use of anthracycline-containing chemotherapy. In general, one has to wait at least 10 years post-treatment to see these effects manifest clinically (131). The use of radiologic methods may allow for the early detection of treatment-associated dysfunction. The vast majority of the available data on RT-induced heart injury use SPECT myocardial perfusion imaging in breast cancer and Hodgkin's disease patients. Recent studies have also investigated the incidence of the cardiac effects of RT in lung and esophageal cancer patients. Finally, preliminary data are available on newer imaging technologies, such as cardiac MRI and PET, for assessing RT-induced cardiac injury in patients with thoracic cancers. However, to our knowledge, there are no published reports using imaging techniques to noninvasively assess radiation-induced cardiotoxicity in preclinical models. Nevertheless, this is likely to become a fruitful area of research in the near future.

\section{Scintigraphy and SPECT}

Nuclear medicine imaging provides both qualitative and quantitative information about regional and global cardiac function (132), and has been suggested to be a sensitive means to assess myocardial injury in patients with coronary artery disease (133). Cardiac SPECT techniques that produce 3D images are currently applied more frequently than are planar scintigraphic techniques; they provide a noninvasive assessment of left ventricular myocardial perfusion and function, such as changes in wall motion and left ventricular ejection fraction. Scans taken in the early years following RT may be useful for estimating subclinical damage. The incidence of perfusion defects appears to be related to the irradiated volume of the left ventricle and largely persists for up to 6 years after RT in breast cancer patients $(134,135)$.

Gyenes et al. conducted a prospective study and performed Tc-99m Sestamibi scintigraphy prior to and $\sim 1$ year after left breast/chest wall RT in 12 patients. Six of the 12 patients (50\%) with some portion of the left ventricle within the radiation field exhibited a new perfusion defect. Again, the location of the defects corresponded with the irradiated volume of the left ventricle. Interestingly, neither electrocardiographic (ECG) changes nor left ventricular segmental wall motion abnormalities were detected by echocardiography (136). Seddon et al. performed SPECT myocardial perfusion imaging in 24 patients with left breast tumors, and 12 control patients with right breast tumors, who had undergone RT at least 5 years previously. Myocardial perfusion defects were found in 17/24 (70.8\%) of left breast patients compared to $2 / 12(16.7 \%)$ of right breast patients. Almost all myocardial defects in left breast patients were located in the cardiac apex, the portion of heart that is incidentally included within the RT fields (137). In a prospective study at Duke, new RT-associated perfusion defects were detected in 16/55 (29\%) of breast cancer patients 6-12 months postRT (Fig. 8). The incidence of perfusion deficits was related to the irradiated volume of the left ventricle, with new defects occurring in approximately $10-20 \%$ and $50-60 \%$ of patients with $<5 \%$ and $>5 \%$ of their left ventricle included within the RT fields, respectively (134). These studies used SPECT images generated without attenuation correction. However, the same technique was used to generate the pre- and post-RT images, and these images were compared to each other. All of the data presented are based on comparisons of pre- vs. postRT images. Thus, the lack of attenuation correction does not explain these findings. For patients who do not experience significant anatomic changes between pre- and post-RT images, attenuation correction does not influence the validity of the results. The accuracy of these studies is dependent on the assumption that there are not meaningful changes in the patient's anatomy in between the pre- and post-RT scans. 
Perfusion defects have been associated with episodes of chest pain and wall motion abnormalities, but their clinical implications are not well understood $(134,135,137,138)$. Further, relatively large perfusion defects appear to cause reductions in the ejection fraction (130), although the data on this point are limited. Abnormalities detected by SPECT have been suggested to be due to attenuation artifacts related to RT-induced pericardial scarring of the breast or chest wall. These artifacts may be misinterpreted as defects in the anterior myocardium (134); however, recent analyses suggest that this is unlikely (139) and that the perfusion changes seen post-RT are "real." Data from several studies relating SPECT changes in the heart of breast cancer and Hodgkin's disease patients, and preliminary data from studies in esophageal and lung cancer patients are shown in Table 2.

\section{MRI}

MRI allows the determination of myocardial wall thickness and, with delayed hyperenhancement, direct visualization of myocardial injury or fibrosis; it is more sensitive than SPECT in assessing sub-endocardial injury. Both MRI and SPECT provide information regarding wall motion and ejection fraction, but MRI has better spatial resolution and thus may be more accurate $(153,154)$. Presently, quantification of myocardial perfusion is better developed with SPECT than with MRI (154).

While MRI provides the ability to globally assess the heart, at this time MRI has only been used to study RT-induced cardiac disease for a small number of lung cancer patients. In pilot studies from MD Anderson Cancer Center and Duke University, no apparent cardiac MRI changes have been observed in a small number of evaluable patients $(151,152)$.

\section{PET}

There is increased interest in the use of PET to provide a map of regional myocardial perfusion because of its improved resolution and accuracy when compared to SPECT. PET has an advantage of possibly shorter exam times than SPECT, but is similarly limited to imaging only the left ventricle (155). A recent case report noted increased FDG uptake within cardiac regions receiving $\geq 25 \mathrm{~Gy} \sim 4$ years earlier; the patient was asymptomatic and had a normal ECG (156).

In summary, imaging has been used to define RT-induced changes in regional perfusion and function in the left ventricle, largely relying on SPECT. Some newer imaging methods may be better able to study RT-induced changes in imaging and function throughout the entire heart. This is critical to better understand the cardiac effects of RT given the multiple cardiac sub-regions and their functional interrelationship/dependency.

\section{SUMMARY}

Technological advances in biomedical imaging have enabled preclinical and clinical studies of radiation-induced normal tissue injury to move from assessing simply anatomical changes to generating functional, microstructural, and metabolic data. Moreover, noninvasive approaches allow the longitudinal determination of the extent and severity of radiationinduced normal tissue injury on an individual basis. Molecular imaging, including MR, SPECT, and PET, holds the promise of identifying the specific targets and biological processes that precede or underlie anatomical and functional changes (157). Recent studies demonstrating, (1) the ability to monitor disease progression and therapy response in neurodegenerative disorders by imaging of peripheral benzodiazepine receptors with PET (158), (2) SPECT imaging of serotonin and dopamine receptors (159), (3) PET and MR imaging of neuroinflammation (160-162), and (4) cardiovascular disease with MR, SPECT, and fluorescent-tagged molecules (163), suggest that applying these techniques to radiation biology/oncology will greatly advance our understanding of the molecular mechanisms 
underlying the development and progression of radiation-induced normal tissue injury. These mechanistic insights will enable radiation oncologists to plan RT regimens more rationally to minimize treatment-related morbidities, as well as intervene to improve the outcome and QOL of their patients.

\section{Acknowledgments}

This work was supported by NIH grant CA112593 and CA122318 (MER), CA119990 (JKBB), CA59827 and CA113699 (CIT), as well as CA69579, DOD (BC010663), and the Lance Armstrong Foundation [LBM].

\section{REFERENCES}

1. Perez, C.; Brady, LW. Principles and Practice of Radiation Oncology. Lippincott-Raven; Philadelphia: 2003.

2. Jemal A, Siegel R, Xu J, Ward E. Cancer statistics. Ca. Cancer J. Clin. 2010; 60:277-300. [PubMed: 20610543]

3. Bentzen SM. Preventing or reducing late side effects of radiation therapy: radiobiology meets molecular pathology. Nat. Rev. Cancer. 2006; 6:702-713. [PubMed: 16929324]

4. Rubin P, Finkelstein J, Shapiro D. Molecular biology mechanisms in the radiation induction of pulmonary injury syndromes: Interrelationship between the alveolar macrophages and the septal fibroblast. Int. J. Radiat. Oncol. Biol. Phys. 1992; 24:93-101. [PubMed: 1512168]

5. Tofilon PJ, Fike JR. The radioresponse of the central nervous system: a dynamic process. Radiat. Res. 2000; 153:357-370. [PubMed: 10798963]

6. Cohen EP, Robbins MEC. Radiation nephropathy. Semin. Nephrol. 2003; 23:486-499. [PubMed: 13680538]

7. Hauer-Jensen M, Wang J, Boerma M, Denham JW. Radiation damage to the gastrointestinal tract: mechanisms, diagnosis, and management. Curr. Opin. Support. Palliat. Care. 2007; 1:23-29. [PubMed: 18660720]

8. Moulder JE, Cohen EP. Future strategies for mitigation and treatment of chronic radiation-induced normal tissue injury. Semin. Radiat. Oncol. 2007; 17:141-148. [PubMed: 17395044]

9. Koo V, Hamilton PW, Williamson K. Non-invasive in vivo imaging in small animal research. Cell. Oncol. 2006; 28:127-139. [PubMed: 16988468]

10. Massoud TF, Gambhir SS. Molecular imaging in living subjects: seeing fundamental biological processes in a new light. Genes Dev. 2003; 17:545-580. [PubMed: 12629038]

11. Sharma N, Neumann D, Macklis R. The impact of functional imaging on radiation medicine. Radiat. Oncol. 2008; 3:25. [PubMed: 18793395]

12. Lawrence YR, Werner-Wasik M, Dicker AP. Biologically conformal treatment: biomarkers and functional imaging in radiation oncology. Future Oncol. 2008; 4:689-704. [PubMed: 18922126]

13. Niu G, Chen X. PET imaging of angiogenesis. PET Clin. 2009; 4:17-38. [PubMed: 20046926]

14. Lapi SE, Voller TF, Welch MJ. PET imaging of hypoxia. PET Clin. 2009; 4:39-47. [PubMed: 20046923]

15. Gropler RJ. PET radiotracers of the cariovascular system. PET Clin. 2009; 4:69-87.

16. Horti AG, Wong DF. Clinical perspective and recent development of PET radioligands for imaging cerebral nicotinic acetylcholine receptors. PET Clin. 2009; 4:89-100. [PubMed: 20046884]

17. Miften MM, Das SK, Su M, Marks LB. Incorporation of functional imaging data in the evaluation of dose distributions using the generalized concept of equivalent uniform dose. Phys. Med. Biol. 2004; 49:1711-1721. [PubMed: 15152926]

18. Kershaw LE, Logue JP, Hutchinson CE, Clarke NW, Buckley DL. Late tissue effects following radiotherapy and neoadjuvant hormone therapy of the prostate measured with quantitative magnetic resonance imaging. Radiother. Oncol. 2008; 88:127-134. [PubMed: 18342969]

19. Diaz S, Casselbrant I, Piltulainen G, Magnusson P, Peterson B, Wollmer P, Leander P, Eckberg O, Akeson P. Hyperpolarized ${ }^{3} \mathrm{He}$ apparent diffusion coefficient MRI of the lung: reproducibility and volume dependency in healthy volunteers and patients with emphysema. J. Magn. Reson. Imaging. 2008; 27:763-770. [PubMed: 18344208] 
20. Madden DJ, Bennett IJ, Song AW. Cerebral white matter integrity and cognitive aging: contributions from diffusion tensor imaging. Neuropsychol. Rev. 2009; 19:415-435. [PubMed: 19705281]

21. Dong Q, Welsh RC, Chenevert TL, Carlos RC, Maly-Sundgren P, Gomez-Hassan DM, Mukherji SK. Clinical applications of diffusion tensor imaging. J. Magn. Reson. Imaging. 2004; 19:6-18. [PubMed: 14696215]

22. van der Graaf M. In vivo magnetic resonance spectroscopy: basic methodology and clinical applications. Eur. Biophys. J. 2010; 39:527-540. [PubMed: 19680645]

23. Cherry SR. Multimodality imaging: beyond PET/CT and SPECT/CT. Semin. Nucl. Med. 2009; 39:348-353. [PubMed: 19646559]

24. Schultheiss TE, Stephens LC. Permanent radiation myelopathy. Br. J. Radiol. 1992; 65:737-753. [PubMed: 1393407]

25. Sheline GE, Wara WM, Smith V. Therapeutic irradiation and brain injury. Int. J. Radiat. Oncol. Biol. Phys. 1980; 6:1215-1218. [PubMed: 7007303]

26. Crossen JR, Garwood D, Glatstein E, Neuwelt EA. Neurobehavioral sequelae of cranial irradiation in adults: a review of radiation-induced encephalopathy. J. Clin. Oncol. 1994; 12:627-642. [PubMed: 8120563]

27. Johannesen TB, Lien HH, Hole KH, Lote K. Radiological and clinical assessment of long-term brain tumour survivors after radiotherapy. Radiother. Oncol. 2003; 69:169-176. [PubMed: 14643954]

28. Giovagnoli AR, Boiardi A. Cognitive impairment and quality of life in long-term survivors of malignant brain tumors. Ital. J. Neurol. Sci. 1994; 15:481-488. [PubMed: 7721551]

29. Meyers CA, Brown PD. Role and relevance of neurocognitive assessment in clinical trials of patients with CNS tumors. J. Clin. Oncol. 2006; 24:1305-1309. [PubMed: 16525186]

30. Oeffinger KC, Mertens AC, Sklar CA, Kawashima T, Hudson MM, Meadows AT, Friedman DL, Marina N, Hobbie W, Robison LL. Chronic health conditions in adult survivors of childhood cancer. N. Engl. J. Med. 2006; 355:1572-1582. [PubMed: 17035650]

31. Mulhern RK, Merchant TE, Gajjar A, Reddick WE, Kun LE. Late neurocognitive sequelae in survivors of brain tumors in childhood. Lancet Oncol. 2004; 5:399-408. [PubMed: 15231246]

32. Nathan PC, Patel SK, Dilley K, Goldsby R, Harvey J, Jacobsen C, Kadan-Lottick N, McKinley K, Millham AK, Armstrong FD. Guidelines for identification of, advocacy for, and intervention in neurocognitive problems in survivors of childhood cancer. Arch. Pediatr. Adolesc. Med. 2007; 161:798-806. [PubMed: 17679663]

33. Butler RW, Haser JK. Neurocognitive effects of treatment for childhood cancer. MRDD Res. Rev. 2006; 12:184-191.

34. Fike JR, Cann C, Davis R, Borich T, Phillips TL, Russell LB. Computed tomography analysis of the canine brain. Effects of hemi-brain X irradiation. Radiat. Res. 1984; 99:294-310. [PubMed: 6463208]

35. Kennedy AS, Archambeau JO, Archambeau M-H, Holshouser B, Thompson J, Moyers M, Hinshaw D, Slater JM. Magnetic resonance imaging as a monitor of changes in the irradiated rat brain. An aid in determining the time course of events in a histologic study. Invest. Radiol. 1995; 30:214-220. [PubMed: 7635670]

36. Ishikawa S, Otsuki T, Kaneki M, Jokura H, Yoshimoto T. Dose-related effects of single focal irradiation in the medial temporal lobe structures in rats-magnetic resonance imaging and histological study. Neurol. Med. Chir. (Toyko). 1999; 39:1-7.

37. Jirák D, Nàmëstková K, Herynek V, Vymazal LR, Mares V, Syková E, Hajak M. Lesion evolution after gamma knife irradiation observed by magnetic resonance imaging. Int. J. Radiat. Biol. 2007; 83:237-244. [PubMed: 17575951]

38. Hecht-Leavitt CC, Grossman RI, Curran WJ Jr. McGrath JT, Jospeh PM, Nelson DF. MR of brain radiation injury: experimental studies in cats. Am. J. Neuroradiol. 1987; 8:427-430. [PubMed: 3111203]

39. Yousem DM, Lenkinski RE, Evans S, Allen D, O’Brien R, Curran W, Schnall M, Bennett M, Wehril SL, Grossman RI. Proton MR spectroscopy of experimental radiation-induced white matter injury. J. Computer Ass. Tomogr. 1992; 16:543-548. 
40. Brennan KM, Roos MS, Budinger TF, Higgins RJ, Wong ST, Bristol KS. A study of radiation necrosis and oedema in the canine brain using positron emission tomography and magnetic resonance imaging. Radiat. Res. 1993; 134:43-53. [PubMed: 8475253]

41. Benczik J, Tenhenen M, Snellman M, Joensuu H, Färkkila M, Joensuu R, Ramadan UA, Kallio M, deGritz B, Morris GM, Hopewell JW. Late radiation effects in the dog brain: correlation of MRI and histological effects. Radiother. Oncol. 63:107-120. (2992). [PubMed: 12065111]

42. Miot E, Hoffschir D, Alapetite C, Gaboriaud G, Pontvert D, Fetisoff F, Le Pape A, Akoka S. Experimental MR study of cerebral radiation injury: quantitative T2 changes over time and histopathologic correlation. Am. J. Neuroradiol. 1995; 16:79-85. [PubMed: 7900606]

43. Jost SC, Hope A, Kiehl E, Perry A, Travers S, Garbow JR. A novel murine model for localized radiation necrosis and its characterization using advanced magnetic resonance imaging. Int. J. Radiat. Oncol. Biol. Phys. 2009; 75:527-533. [PubMed: 19735877]

44. Shaw EG, Rosdahl R, D’Agostino RB, Lovato J, Naughton M, Robbins ME, Rapp SR. Phase II study of donepezil in irradiated brain tumor patients: effect on cognitive function, mood, and quality of life. J. Clin. Oncol. 2006; 24:1415-1420. [PubMed: 16549835]

45. Robbins ME, Payne V, Tommasi E, Diz DI, Hsu F-C, Brown WR, Wheeler KT, Olson J, Zhao W. The AT1 receptor antagonist, L-158,809, prevents or ameliorates fractionated whole-brain irradiation-induced cognitive impairment. Int. J. Radiat. Oncol. Biol. Phys. 2009; 73:499-505. [PubMed: 19084353]

46. Shi L, Linville MC, Iversen E, Molina DP, Yester J, Wheeler KT, Robbins ME, Brunso-Bechtold JK. Maintenance of white matter integrity in a rat model of radiation-induced cognitive impairment. J. Neurol. Sci. 2009; 285:178-184. [PubMed: 19625028]

47. Le Bihan D, Mangin JF, Poupon C, Clark CA, Pappata S, Molko N, Chabriat H. Diffusion tensor imaging: concepts and applications. J. Magn. Reson. Imaging. 2001; 13:534-546. [PubMed: 11276097]

48. Chan KC, Khong PL, Cheung MM, Wang S, Cai KX, Wu EX. MRI of late microstructural and metabolic alterations in radiation-induced brain injuries. J. Magn. Reson. Imaging. 2009; 29:10131020. [PubMed: 19388094]

49. Song SK, Sun SW, Ramsbottom MJ, Chang C, Russell J, Cross AH. Dysmyelination revealed through MRI as increased radial (but unchanged axial) diffusion of water. Neuroimage. 2002; 17:1429-1436. [PubMed: 12414282]

50. Song SK, Yoshino J, Le TQ, Lin SJ, Sun SW, Cross AH, Armstrong RC. Demyelination increases radial diffusivity in corpus callosum of mouse brain. Neuroimage. 2005; 26:132-140. [PubMed: 15862213]

51. Nagesh V, Tsien CI, Chenevert TL, Ross BD, Lawrence TS, Junick L, Cao Y. Radiation-induced changes in normal-appearing white matter in patients with cerebral tumors: a diffusion tensor imaging study. Int. J. Radiat. Oncol. Biol. Phys. 2008; 70:1002-1010. [PubMed: 18313524]

52. Khong P-L, Leung LH, Fung AS, Fong DY, Qiu D, Kwong DL, Ooi GC, McAlanon G, Cao G, Chan GC. White matter anisotropy in post-treatment childhood cancer survivors: preliminary evidence of association with neurocognitive function. J. Clin. Oncol. 2006; 24:884-890. [PubMed: 16484697]

53. Qiu D, Kwong DL, Chan GC, Leung LH, Khong P-L. Diffusion tensor magnetic resonance imaging finding of discrepant fractional anisotropy between the frontal and parietal lobes after whole-brain irradiation in childhood medulloblastoma survivors: reflection of regional white matter radiosensitivity? Int. J. Radiat. Oncol. Biol. Phys. 2007; 69:846-851. [PubMed: 17544593]

54. Dellani PR, Eder S, Gawehn J, Vucurevic G, Fellgiebel A, Mûller MJ, Schmidberger H, Stoeter P, Gutjahr P. Late structural alterations of cerebral white matter in long-term survivors of childhood leukemia. J. Magn. Reson. Imaging. 2008; 27:1250-1255. [PubMed: 18504742]

55. Haris M, Kumar S, Raj MK, Das KJ, Sapru S, Behari S, Rathore RK, Narayan PA, Gupta RK. Serial diffusion tensor imaging to characterize radiation-induced changes in normal-appearing white matter following radiotherapy in patients with adult low-grade gliomas. Radiat. Med. 2008; 26:140-150. [PubMed: 18683569] 
56. Wang S, Wu EX, Qiu D, Leung LHT, Lau H-F, Khong P-L. Longitudinal diffusion tensor magnetic resonance imaging study of radiation-induced white matter damage in a rat model. Cancer Res. 2000; 69:1190-1198. [PubMed: 19155304]

57. Peiffer AM, Shi L, Olson J, Brunso-Bechtold JK. Differential effects of radiation and age on diffusion tensor imaging in rats. Brain Res. 2010; 1351:23-31. [PubMed: 20599817]

58. Nagesh V, Tsien CI, Sundgren PC, Buchtel HA, Chenevert TL, Junck L, Rogers L, Lawrence TS, Cao Y. Diffusion tensor imaging as a biomarker for neurotoxicity of radiation. Int. J. Radiat. Oncol. Biol. Phys. 2008; 72(Suppl. 1):S529.

59. Hsu F, Carolan H, Nichol A, Cao F, Nuraney N, Lee R, Gete E, Wong F, Schmuland M, Otto K. Whole brain radiotherapy with hippocampal avoidance and simultaneous integrated boost for 1-3 brain metastases: a feasibility study using volumetric modulated arc therapy. Int. J. Radiat. Oncol. Biol. Phys. 2010; 76:1480-1485. [PubMed: 19625140]

60. Yuan H, Gaber MW, Boyd K, Wilson CM, Kiani MF, Merchant TE. Effects of fractionated radiation on the brain vasculature in a murine model: blood-brain barrier permeability, astrocyte proliferation, and ultrastructural changes. Int. J. Radiat. Oncol. Biol. Phys. 2006; 66:860-866. [PubMed: 17011458]

61. Brown WR, Thore CR, Moody DM, Robbins ME, Wheeler KT. Vascular damage after fractionated whole-brain irradiation in rats. Radiat. Res. 2005; 164:662-668. [PubMed: 16238444]

62. Reinhold HS, Calvo W, Hopewell JW, van den Berg AP. Development of blood vessel-related radiation damage in the fimbria of the central nervous system. Int. J. Radiat. Oncol. Biol. Phys. 1990; 18:37-42. [PubMed: 2298633]

63. Li YQ, Chen P, Haimovitz-Friedman A, Reilly RM, Wong CS. Endothelial apoptosis initiates acute blood-brain barrier disruption after ionizing radiation. Cancer Res. 2003; 63:5950-5956. [PubMed: 14522921]

64. Tofts PS, Brix G, Buckley DL, Evolhoch JL, Henderson E, Knopp MV, Larsson HB, Lee TY, Mayr NA, Weisskoff RM. Estimating kinetic parameters from dynamic contrast-enhanced T(1)weighted MRI of a diffusable tracer: standardized quantities and symbols. J. Magn. Reson. Imaging. 1999; 10:223-232. [PubMed: 10508281]

65. Cao Y, Tsien CI, Sundgren PC, Nagesh V, Normolle D, Buchtel H, Junck L, Lawrence TS. Dynamic contrast-enhanced magnetic resonance imaging as a biomarker for prediction of radiation-induced neurocognitive dysfunction. Clin. Cancer Res. 2009; 15:1747-1754. [PubMed: 19223506]

66. Hoehn M, Nicolay K, Franke C, van der Sanden B. Application of magnetic resonance to animal models of cerebral ischemia. J. Magn. Reson. Imaging. 2001; 14:491-509. [PubMed: 11747001]

67. Gillies RJ, Morse D. In vivo magnetic resonance spectroscopy in cancer. Annu. Rev. Biomed. Eng. 2005; 7:287-326. [PubMed: 16004573]

68. Chong VFH, Khoo JBK, Chan LL, Rumpel H. Neurological changes following radiation therapy for head and neck tumours. Eur. J. Radiol. 2002; 44:120-129. [PubMed: 12413680]

69. Schlemmer H-P, Bachert P, Henze M, Buslei R, Herfart KK, Debus J, van Kaick G. Differentiation of radiation necrosis from tumor progression using proton magnetic resonance spectroscopy. Neuroradiology. 2002; 44:216-222. [PubMed: 11942375]

70. Herynek V, Burian M, Jirák D, Liscák R, Námêstková K, Hájek M, Sokova E. Metabolite and diffusion changes in the rat brain after Leksell Gamma Knife irradiation. Magn. Reson. Med. 2004; 52:397-402. [PubMed: 15282823]

71. Sundgren PC, Nagesh V, Elais A, Tsien C, Junck L, Gomez Hassan DM, Lawrence TS, Chenevert TL, Rogers L, Hassan G. Metabolic alterations: a biomarker for radiation-induced normal brain injury-an MR spectroscopy study. J. Magn. Reson. Imaging. 2009; 29:291-297. [PubMed: 19161192]

72. Estève F, Rubin C, Grand S, Kolodié H, Le Bas JF. Transient metabolic changes observed with proton MR spectroscopy in normal brain after radiation therapy. Int. J. Radiat. Oncol. Biol. Phys. 1998; 40:279-286. [PubMed: 9457810]

73. Lee MC, Pirzkall A, McKnight TR, Nelson SJ. 1H-MRSI of radiation effects in normal-appearing white matter: dose-dependence and impact on automated spectral classification. J. Magn. Reson. Imaging. 2004; 19:379-388. [PubMed: 15065160] 
74. Virta A, Patronas N, Raman R, Dwyer A, Barnett A, Bonavita S, Tedeschi G, Lundbom N. Spectroscopic imaging of radiation-induced effects in the white matter of glioma patients. Magn. Reson. Imaging. 2000; 18:851-857. [PubMed: 11027879]

75. Walecki J, Sokól M, Pieniazek P, Maciejewski B, Tarnawski R, Kripska T, Wydmanski J, Brzezinski J, Grieb P. Role of short TE 1H-MR spectroscopy in monitoring of post-operation irradiated patients. Eur. J. Radiol. 1999; 30:154-161. [PubMed: 10401596]

76. Chan YL, Roebuck DJ, Yuen MP, Yeung KW, Lau KY, Li CK, Chik KW. Long-term cerebral metabolite changes on proton magnetic resonance spectroscopy in patients cured of acute lymphoblastic leukemia with previous intrathecal methotrexate and cranial irradiation prophylaxis. Int. J. Radiat. Oncol. Biol. Phys. 2001; 50:759-763. [PubMed: 11395245]

77. Sundgren PC, Cao Y. Brain irradiation: effects on normal brain parenchyma and radiation injury. Neuroimag. Clin. N. Am. 2009; 19:657-668.

78. Pasantes-Morales H, Franco R, Torres-Marquez E, Hernandez-Fonsec K, Ortega A. Amino acid osmolytes in regulatory volume decrease and isovolumetric regulation in brain cells: contribution and mechanisms. Cell. Physiol. Biochem. 2000; 10:61-70.

79. Atwood T, Payne VS, Zhao W, Brown WR, Wheeler KT, Zhu J-M, Robbins ME. Quantitative magnetic resonance spectroscopy reveals a potential relationship between radiation-induced changes in rat brain metabolites and cognitive impairment. Radiat. Res. 2007; 168:574-581. [PubMed: 17973545]

80. Robbins ME, Bourland JD, Cline JM, Wheeler KT, Deadwyler SA. A model for assessing cognitive impairment after fractionated whole-brain irradiation in nonhuman primates. Radiat. Res. 2011; 175:519-525. [PubMed: 21275607]

81. Silverman DHS, Mosconi L, Ercoli L, Chen W, Small GW. Positron emission tomography scans obtained for the evaluation of cognitive dysfunction. Semin. Nucl. Med. 2008; 38:251-261. [PubMed: 18514081]

82. Iaria G, Prerides M, Daghyer A, Pike B, Bohbot VD. Cognitive strategies dependent on the hippocampus and caudate nucleus in human navigation: variability and change with practice. $\mathrm{J}$. Neurosci. 2003; 23:5945-5952. [PubMed: 12843299]

83. Izquierdo A, Suda RK, Murray EA. Comparison of the effects of bilateral orbital prefrontal cortex lesions and amygdala lesions on emotional responses in rhesus monkeys. J. Neurosci. 2005; 25:8534-8542. [PubMed: 16162935]

84. Baillieux H, De Smet HJ, Paquier PF, De Deyn PP, Mariën P. Cerebellar neurocognition: insights into the bottom of the brain. Clin. Neurol. Neurosurg. 2008; 110:763-773. [PubMed: 18602745]

85. Marks LB, Fan M, Clough R, Munley MT, Bentel G, Coleman RE, Jaszczak R, Hollis D, Anscher M. Radiation-induced pulmonary injury: symptomatic versus subclinical endpoints. Int. J. Radiat. Biol. 2000; 76:469-475. [PubMed: 10815626]

86. Goethals I, Dierckx R, De Meerieer G, De Sutter J, De Winter O, De Neve W, Van de Wiele C. The role of nuclear medicine in the prediction and detection of radiation-associated normal pulmonary and cardiac damage. J. Nucl. Med. 2003; 44:1531-1539. [PubMed: 12960203]

87. Graham MV, Purdy JA, Emami B, Harms W, Bosch W, Lockett MA, Perez CA. Clinical dosevolume histogram analysis for pneumonitis after 3D treatment for nonsmall cell lung cancer (NSCLC). Int. J. Radiat. Oncol. Biol. Phys. 1999; 45:323-329. [PubMed: 10487552]

88. Dörr W, Bertmann S, Hermann T. Radiation induced lung reactions in breast cancer therapy. Modulating factors and consequential effects. Strahlenther. Onkol. 2005; 181:567-573. [PubMed: 16170483]

89. Cazzaniga LF, Bossi A, Cosentino D, Frigerio M, Martinelli A, Monti A, Morresi A, Ostinelli A, Scandolaro I, Besana G. Radiological findings when very small lung volumes are irradiated in breast and chest wall treatment. Radiat. Oncol. Invest. 1998; 6:58-62.

90. Kuhnt T, Richter C, Enke H. Acute radiation reaction and local control in breast cancer patients treated with postmastectomy radiotherapy. Strahlenther. Onkol. 1998; 174:257-261. [PubMed: 9614954]

91. Rotstein S, Lax I, Savane G. Influence of radiation therapy on the lung-tissue in breast cancer patients: CT-assessed density changes and associated symptoms. Int. J. Radiat. Oncol. Biol. Phys. 1990; 18:173-180. [PubMed: 2298619] 
92. Schratter-Sehn AU, Schurawitzki H, Zach M, Schratter M. High-resolution computed tomography of the lungs in irradiated breast cancer patients. Radiother. Oncol. 1993; 27:198-202. [PubMed: 8210455]

93. Lind PA, Wennberg B, Gagliardi G, Rosfors S, Blom-Goldman U, Lidestâhl A, Svane G. ROC curves and evaluation of radiation-induced pulmonary toxicity in breast cancer. Int. J. Radiat. Oncol. Biol. Phys. 2006; 64:765-770. [PubMed: 16257129]

94. Evans ES, Hahn CA, Kocak Z, Zhou S-M, Marks LB. The role of functional imaging in the diagnosis and management of late normal tissue injury. Semin. Radiat. Oncol. 2007; 17:72-80. [PubMed: 17395037]

95. Tokatli F, Kaya M, Kocak Z, Ture M, Mert S, Unle E, Alkaya F, Cakir B. Sequential pulmonary effects of radiotherapy detected by functional and radiological end points in women with breast cancer. Clin. Oncol. (R. Coll. Radiol.). 2005; 17:39-46. [PubMed: 15714928]

96. Rosen FTA II, Antolak JA, Starkschall G, Travis EL, Tucker SL, Hogstrom KR, Cox JD, Komaki R. Correlation between lung fibrosis and radiation therapy dose after concurrent radiation therapy and chemotherapy for limited small cell lung cancer. Radiology. 2001; 221:614-622. [PubMed: 11719654]

97. Theuws JC, Kwa SL, Boersma LJ, Damen EM, Muller SH, Baas P, Lebesque JV. Dose-effect relations for early local pulmonary injury after irradiation for malignant lymphoma and breast cancer. Radiother. Oncol. 1998; 48:33-43. [PubMed: 9756170]

98. Trask CW, Joannides T, Harper PG, Tobias JS, Spiro SG, Geddes DM, Southami RL, Beverly PC. Radiation-induced lung fibrosis after treatment of small cell carcinoma of the lung with high-dose cyclophosphamide. Cancer. 1985; 55:57-60. [PubMed: 2981141]

99. Abid SH, Malhotra V, Perry MC. Radiation-induced and chemotherapy-induced pulmonary injury. Curr. Opin. Oncol. 2001; 13:242-248. [PubMed: 11429481]

100. Levinson B, Marks LB, Munley MT, Poulson J, Hollis D, Jaszczak R, Coleman RE. Regional dose response to pulmonary irradiation using a manual method. Radiother. Oncol. 1998; 48:5360. [PubMed: 9756172]

101. Koenig TR, Munden RF, Erasmus JJ, Sabioff BS, Gladish GW, Komaki R, Stevens CW. Radiation injury of the lung after three-dimensional conformal radiation therapy. Am. J. Roentgenol. 2002; 178:1383-1388. [PubMed: 12034601]

102. Kocak, Z.; Sullivan, D.; Marks, LB. The role of imaging in the study of radiation-induced normal tissue injury. In: Rubin, R.; Marks, LB.; Okunieff, P., editors. Late effects of cancer treatment on normal tissue injury. Vol. Vol 1. Springer; Berlin: 2008. p. 37-45.

103. el-Khatib E, Sharplin J, Battista J. The density of mouse lung in vivo following X irradiation. Int. J. Radiat. Oncol. Biol. Phys. 1983; 9:853-858. [PubMed: 6863058]

104. Lehnert S, el-Khatib E. The use of CT densitometry in the assessment of radiation-induced damage to the rat lung: a comparison with other endpoints. Int. J. Radiat. Oncol. Biol. Phys. 1989; 16:117-124. [PubMed: 2912932]

105. Nicholas D, Down JD. The assessment of early and late radiation injury to the mouse lung using X-ray computerised tomography. Radiother. Oncol. 1985; 4:253-263. [PubMed: 4081113]

106. Ghobadi G, Hogeweg LE, Faber H, Tukker WGJ, Schippers JM, Brandenburg S, Langendijk JA, Coppes RP, van Luijk PS. Quantifying local radiation-induced lung damage from computed tomography. Int. J. Radiat. Oncol. Biol. Phys. 2010; 76:548-556. [PubMed: 20117290]

107. Ward WF. Radiation-induced pulmonary arterial perfusion defects: modification by Dpenecillamine. Radiology. 1981; 139:201-204. [PubMed: 7208923]

108. Fleckenstein K, Zgonijanin L, Chen L, Rabbani Z, Jackson IL, B Thrasher, Kirkpatrick BJ, Foster WM, Vujaskovic Z. Temporal onset of hypoxia and oxidative stress after pulmonary irradiation. Int. J. Radiat. Oncol. Biol. Phys. 2007; 68:196-204. [PubMed: 17448873]

109. Boersma LJ, Damen EM, de Boer RW, Muller SH, Valdés-Olmos RA, van Zandwijk N, Lebesque JV. Recovery and overall and local lung function loss 18 months after irradiation for malignant lymphoma. J. Clin. Oncol. 1996; 14:1431-1441. [PubMed: 8622056]

110. Mah K, Van Dyk J, Keane T, Poon PY. Acute radiation-induced pulmonary damage: A clinical study on the response to fractionated radiation therapy. Int. J. Radiat. Oncol. Biol. Phys. 1987; 13:179-188. [PubMed: 3818385] 
111. Seppenwoolde Y, Muller SH, Theuws JC, Baas P, Belderbos JS, Boersma LJ, Lebesque JV. Radiation dose-effect relations and local recovery in perfusion for patients with nonsmall-cell lung cancer. Int. J. Radiat. Oncol. Biol. Phys. 2000; 47:681-690. [PubMed: 10837952]

112. Theuws JC, Seppenwoolde Y, Kwa ST, Boersma LJ, Damen EM, Baas P, Muller SH, Lebesque JV. Changes in local pulmonary injury up to 48 months after irradiation for lymphoma and breast cancer. Int. J. Radiat. Oncol. Biol. Phys. 2000; 47:1201-1208. [PubMed: 10889373]

113. Woel RT, Munley MT, Hollis D, Fan M, Bentel G, Anscher MS, Shafman T, Coleman RE, Jaszczak RJ, Marks LB. The time course of radiation therapy-induced reductions in regional perfusion: a prospective study with >5 years of follow-up. Int. J. Radiat. Oncol. Biol. Phys. 2002; 52:58-67. [PubMed: 11777622]

114. Marks LB, Yu X, Vujaslovic Z. Radiation-induced lung injury. Semin. Radiat. Oncol. 2003; 13:333-345. [PubMed: 12903021]

115. Seppenwoolde Y, De Jaeger K, Boersma LJ, Belderbos JS, Lebesque JV. Regional differences in lung radiosensitivity after radiotherapy for nonsmall-cell lung cancer. Int. J. Radiat. Oncol. Biol. Phys. 2004; 60:748-758. [PubMed: 15465191]

116. Fan M, Marks LB, Hollis D, Bentel GG, Anscher MS, Sibley G, Coleman RE, Jaszczak RJ, Munley MT. Can we predict radiation-induced changes in pulmonary function based on the sum of predicted regional dysfunction? J. Clin. Oncol. 2001; 19:543-550. [PubMed: 11208849]

117. Fan M, Marks LB, Lind P, Hollis D, Woel RT, Bentel GG, Anscher MS, Shafman TD, Coleman RE, Jaszczak RJ, Munley MT. Relating radiation-induced regional lung injury to changes in pulmonary function tests. Int. J. Radiat. Oncol. Biol. Phys. 2001; 51:311-317. [PubMed: 11567804]

118. Theuws JC, Kwa SL, Wagenaar AC, Seppenwoolde Y, Boersma LJ, Damen EM, Muller SH, Baas P, Lebesque JV. Prediction of overall pulmonary function loss in relation to the 3-D dose distribution for patients with breast cancer and malignant lymphoma. Radiother. Oncol. 1998; 49:233-243. [PubMed: 10075256]

119. Gopal R, Tucker SL, Komaki R, Liao Z, Forster KM, Stevens C, Kelly JF, Starkschall G. The relation between local dose and loss of function for irradiated lung. Int. J. Radiat. Oncol. Biol. Phys. 2003; 56:106-113. [PubMed: 12694828]

120. Aoki T, Nagata Y, Negoro Y, Takayama K, Mizowaki T, Kokubo M, Gya N, Mitsumori M, Hiraoka M. Evaluation of lung injury after three-dimensional conformal stereotactic radiation therapy for soliaty lung cancers: CT appearance. Radiology. 2004; 230:101-108. [PubMed: 14645881]

121. Shioya S, Tsuji C, Kurita D, Tsuda M, Haida M, Kawana A, Ohta Y. Early damage to lung tissue after irradiation detected by the magnetic resonance T2 relaxation time. Radiat. Res. 1997; 148:359-364. [PubMed: 9339952]

122. Ogasawara N, Suga K, Karino Y, Matsunaga N. Perfusion characteristics of radiation-induced lung on Gd-DTPA-enhanced dynamic magnetic resonance imaging. Invest. Radiol. 2002; 37:448-457. [PubMed: 12138361]

123. Yankelevitz DF, Henschke CI, Batata M, Kim YS, Chu F. Lung cancer: evaluation with MR imaging during and after irradiation. J. Thorac. Imaging. 1994; 9:41-46. [PubMed: 8114164]

124. Murayama S, Akamine T, Sakai S, Oshiro Y, Kakinohana Y, Soeda H, Toita T, Adachi GH. Risk factor of radiation pneumonitis: assessment with velocity-encoded cine magnetic resonance imaging of pulmonary artery. J. Computer Ass. Tomogr. 2004; 28:204-208.

125. Hart JP, McCurdy MR, Ezhil M, Wei W, Khan M, Luo D, Munden RF, Johnson VE, Guerrero TM. Radiation pneumonitis: correlation of toxicity with pulmonary metabolic radiation response. Int. J. Radiat. Oncol. Biol. Phys. 2008; 71:967-971. [PubMed: 18495373]

126. Hubbs, JL.; Nam, J.; Zhou, S.; Hahn, CA.; Marks, LB. Bioimaging in vivo to discern the evolution of late effects temporally and spatially. In: Rubin, P.; Constine, LS.; Marks, LB.; Okunieff, P., editors. Cured II - LENT Cancer Survivorship Research and Education. Springer; Berlin Heidelberg: 2008. p. 7-23.

127. Polansky SM, Ravin CE, Prosnitz LR. Pulmonary changes after primary irradiation for early breast cancer carcinoma. Am. J. Roentgenol. 1980; 134:101-105. [PubMed: 6243202] 
128. Allavena C, Conroy T, Aletti P, Bey P, Lederlin P. Late pulmonary toxicity after treatment for Hodgkin's disease. Br. J. Cancer. 1992; 65:908-912. [PubMed: 1616862]

129. Hicks RJ, MacManus MP, Matthews JP, Hogg A, Binns D, Rischin D, Ball DL, Peters LJ. Early FDG-PET imaging after radical radiotherapy for nonsmall-cell lung cancer: inflammatory changes in normal tissues correlate with tumor response and do not confound therapeutic response evaluation. Int. J. Radiat. Oncol. Biol. Phys. 2004; 60:412-418. [PubMed: 15380574]

130. Guerrero T, Johnson V, Hart J, Pan T, Khan M, Luo D, Liao Z, Alani J, Stevens C, Komaki R. Radiation pneumonitis: local dose versus [18F]-fluorodeoxyglucose uptake response in irradiated lung. Int. J. Radiat. Oncol. Biol. Phys. 2007; 68:1030-1035. [PubMed: 17398033]

131. Darby SC, McGale P, Taylor CW, Peto R. Long-term mortality from heart disease and lung cancer after radiotherapy for early breast cancer: prospective cohort study of about 300,000 women in US SEER cancer registries. Lancet Oncol. 2005; 6:557-565. [PubMed: 16054566]

132. Hardenbergh PH, Munley MT, Bentel GC, Kedem R, Borges-Neto S, Hollis D, Prosnitz LR, Marks LB. Cardiac perfusion changes in patients treated for breast cancer with radiation therapy and doxorubicin: preliminary results. Int. J. Radiat. Oncol. Biol. Phys. 2001; 49:1023-1028. [PubMed: 11240243]

133. Hundley GW, Morgan TM, Neagle CM, Hamilton CA, Rerkpattanapipat P, Link KM. Magnetic resonance imaging determination of cardiac prognosis. Circulation. 2002; 106:2328-2333. [PubMed: 12403662]

134. Marks LB, Yu X, Prosnitz RG, Zhou S-M, Hardenbergh PH, Blazing M, Hollis D, Lind P, Tisch A, Wong TZ, Borges-Neto S. The incidence and functional consequences of RT-associated cardiac perfusion defects. Int. J. Radiat. Oncol. Biol. Phys. 2005; 63:214-223. [PubMed: 16111592]

135. Prosnitz RG, Hubbs LJ, Evans ES, Zhou SM, Yu X, Blazing MA, Hollis DR, Tisch A, Wong TZ, Hardenbergh S. Prospective assessment of radiotherapy-associated cardiac toxicity in breast cancer patients: analysis of data 3 to 6 years after treatment. Cancer. 2007; 110:1840-1850. [PubMed: 17763369]

136. Gyenes G, Fornander T, Carlens P, Glasand U, Rutqvist LE. Myocardial damage in breast cancer patients treated with adjuvant radiotherapy: a prospective study. Int. J. Radiat. Oncol. Biol. Phys. 1996; 36:899-905. [PubMed: 8960519]

137. Seddon B, Cook A, Gothard L, Salmon E, Latus K, R. S, Yarnold J. Detection of defects in myocardial perfusion imaging in patients with early breast cancer treated with radiotherapy. Radiother. Oncol. 2002; 64:53-63. [PubMed: 12208576]

138. Yu X, Prosnitz LR, Zhou S, Hardenbergh PH, Tisch A, Blazing MA, Borges-Neto S, Hollis D, Wong T, Marks LB. Symptomatic cardiac events following radiation therapy for left-sided breast cancer: possible association with radiation therapy-induced changes in regional perfusion. Clin. Breast Cancer. 2003; 4:193-197. [PubMed: 14499012]

139. Lawrence MV, Roper J, Bateman T, Bailey J, Fried D, Wong T, Jaszcak R, Das S, Zhou S, Marks L. Can density changes of surrounding soft tissues cause post-RT cardiopulmonary perfusion defects? Int. J. Radiat. Oncol. Biol. Phys. 2010; 78(Suppl. 1):S47.

140. Gyenes G, Fornander T, Carlens P, Rutqvist LE. Morbidity of ischemic heart disease in early breast cancer 15-20 years after adjuvant radiotherapy. Int. J. Radiat. Oncol. Biol. Phys. 1994; 28:1235-1241. [PubMed: 8175411]

141. Gusstavsson A, Bendahl PG, Cwikiel M, Eskilsson J, Thapper KL, Pahlm G. No serious late cardiac effects after adjuvant radiotherapy following mastectomy in premenopausal women with early breast cancer. Int. J. Radiat. Oncol. Biol. Phys. 1999; 43:745-754. [PubMed: 10098429]

142. Hojris I, Sand NP, Andersen J, Rehling M, Overgaard M. Myocardial perfusion imaging in breast cancer patients trested with or without post-mastectomy radiotherapy. Radiother. Oncol. 2000; 55:163-172. [PubMed: 10799728]

143. Cowen D, Gonzague-Casabianca L, Brenot-Rossi I, Viends P, Mace L, Levi-Hannoun JM, Alzieu C, Resbeut M. Thallium-201 perfusion scintigraphy in the evaluation of late myocardial damage in left-side breast cancer treated with adjuvant radiotherapy. Int. J. Radiat. Oncol. Biol. Phys. 1998; 41:809-815. [PubMed: 9652842] 
144. Girinsky T, Cordova A, Rey A, Cosset JM, Tertian G, Pierga JV. Thalium-201 scintigraphy is not predictive of late cardiac complications in patients with Hodgkin's desease treated with mediastinal radiation. Int. J. Radiat. Oncol. Biol. Phys. 2000; 48:1503-1506. [PubMed: 11121655]

145. Savage DE, Constine LS, Schwartz RG, Rubin P. Radiation effects on left ventricular function and myocardial perfusion on long term survivors of Hodgkin's disease. Int. J. Radiat. Oncol. Biol. Phys. 1990; 19:721-727. [PubMed: 2211221]

146. Gustavsson A, Eskilsson J, Landberg T, Svahn-Tapper G, White T, Wollmer P, Akerman M. Late cardiac effects after mantle radiootherapy in patients with Hodgkin's disease. Ann. Oncol. 1990; 1:355-363. [PubMed: 2261376]

147. Maunoury C, Pierga JY, Valette H, Tchernia G, Cosset JM, Desgrez A. Myocardial perfusion damage after mediastinal irradiation for Hodgkin's disease: a thallium-201 single photon emission tomography study. Eur. J. Nucl. Med. 1992; 19:871-873. [PubMed: 1451703]

148. Glanzmann C, Kaufmann P, Jenni R, Hess OM, Hugenin P. Cardiac risk after mediastinal irradiation for Hodgkin's disease. Radiother. Oncol. 1998; 46:51-62. [PubMed: 9488128]

149. Heidenreich PA, Schnittger I, Strauss HW, Vagelos RH, Lee BK, Mariscal CS, Tate DJ, Horning SJ, Hoppe RT, Hancock SL. Screening for coronary disease after mediastinal irradiation for Hodgkin's disease. J. Clin. Oncol. 2007; 25:43-49. [PubMed: 17194904]

150. Gayed IW, Liu HH, Yusuf SW, Komaki R, Wei X, Wang X, Chang JY, Swafford J, Broemeling $\mathrm{L}$, Liao Z. The prevelance of myocardial ischemia after concurrent chemo-radiation therapy as detected by gated myocardial perfusion imaging in patients with esophageal cancer. J. Nucl. Med. 2006; 47:1756-1762. [PubMed: 17079807]

151. Lind PA, Larsson T, Lidestahl A. Cardiac changes on MRI and SPECT after definitive radiotherapy in patients with lung cancer. J. Clin. Oncol. 2006; 24:17059.

152. Hubbs JL, Zhou S, Hurwitz LM, Ma J, Borges-Neto S, Kelsey CR, Larrier NA, Blazing MA, Marks LB. The prospective assessment of RT-associated changes in myocardial perfusion and function in patients irradiated for thoracic malignancies. Int. J. Radiat. Oncol. Biol. Phys. 2008; 78:S118-S119.

153. Wagner A, Marholdt H, Kim RJ, Judd RM. Use of cardiac magnetic resonance to assess viability. Curr. Cardiol. Rep. 2005; 5:59-64. [PubMed: 15610650]

154. Cuocolo A, Acampa W, Imbriaco M, De Luca N, Iovino GL, Salvatore M. The many ways to myocardial perfusion imaging. Q. J. Nucl. Med. Mol. 2005; 49:4-18.

155. Chua SC, Ganatra RH, Green DJ. Nuclear cardiology: myocardial perfusion imaging with SPECT and PET. Imaging. 2006; 18:166-177.

156. Zöphel K, Hölzel C, Dawel M, Hölscher T, Evers C, Kotzerke J. PET/CT demonstrates increased myocardial FDG uptake following irradiation therapy. Eur. J. Nucl. Med. Mol. Imaging. 2007; 34:1322-1323. [PubMed: 17546454]

157. Taghva A, Kim PE, Liu CY, Apuzzo ML. Molecular imaging, Part 1: Apertures into the landscape of genomic medicine. World Neurosurg. 2010; 73:307-316. [PubMed: 20849785]

158. Peremans K, Goethals I, De Vos F, Dobbeleir A, Ham H, Van Bree H, Van Heeringen C, Audenaert K. Serotonin transporter and dopamine transporter imaging in the canine brain. Nucl. Med. Biol. 2006; 33:907-913. [PubMed: 17045171]

159. Doorduin J, de Vries EF, Dierckx RA, Klein HC. PET imaging of the peripheral benzodiazepine receptor: monitoring disease progression and therapy response in neurodegenerative disorders. Curr. Pharm. Des. 2008; 14:3297-3315. [PubMed: 19075709]

160. Kannan S, Balakrishnan B, Muzik O, Romero R, Chugani D. Positron emission tomography imaging of neuroinflammation. J. Child. Neurol. 2009; 24:1190-1199. [PubMed: 19745091]

161. Van Camp N, Boisgard R, Kuhnast B, Thézé B, Viel T, Grégoire M-C, Chauveau F, Boutin H, Katsifis A, Dolle F, Tavatian B. In vivo imaging of neuroinflammation: a comparative study between $\left[{ }^{18} \mathrm{~F}\right]$ PBR111, $\left[{ }^{11} \mathrm{C}\right] \mathrm{CLINME}$ and $\left[{ }^{11} \mathrm{C}\right] \mathrm{PK} 11195$ in an acute rodent model. Eur. J. Nucl. Med. Mol. Imaging. 2010; 37:962-972. [PubMed: 20069292]

162. Stoll G, Bendzus M. Imaging of inflammation in the peripheral and central nervous system by magnetic resonance imaging. Neuroscience. 2009; 158:1151-1160. [PubMed: 18651996] 
163. Dobrucki LW, Sinusas AJ. PET and SPECT in cardiovascular molecular imaging. Nat. Rev. Cardiol. 2010; 7:38-47. [PubMed: 19935740] 


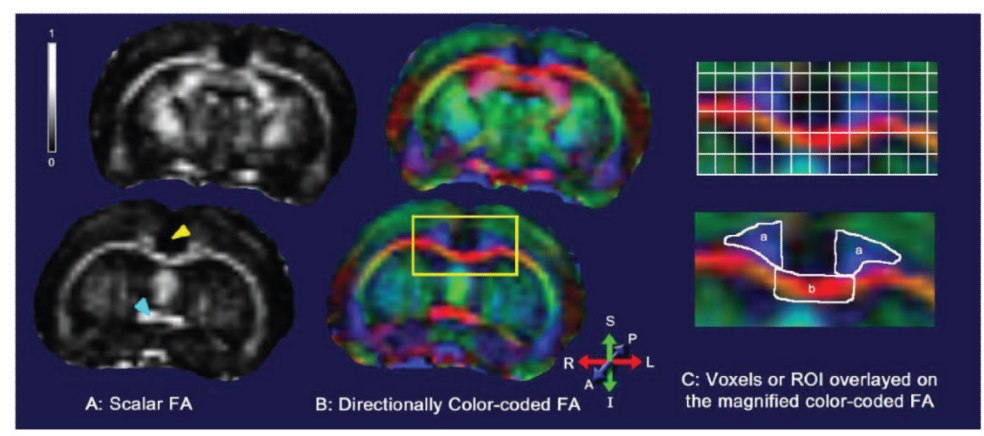

FIG. 1.

Coronal brain slices of a male Fischer $344 \times$ Brown Norway rat. Panel A: Fractional Anisotropy (FA) indicates the directional water diffusion within a voxel. Fractional anisotropy values approaching 1 (aqua arrowhead) have high directional flow and can be seen within white matter tracts throughout the rat brain. Panel B: Fractional anisotropy can be colored to represent the direction of flow throughout the 3D image. In this example, blue defines flow between anterior (A) and posterior (P), red defines flow between left $(\mathrm{L})$ and right (R), and green defines flow between superior (S) and inferior (I). Colors in between these axes represent the entire color spectrum applied in $360^{\circ}$. Panel C: To compare voxelwise and region of interest (ROI) analysis, a medial region of the lower panel from part B has been magnified. Voxel analysis will compare across individuals the area of tissue that is contained within each voxel and relies on voxels being in the same region across all subjects. As can be seen, structures are split across voxels creating partial volumes, which contain two or more tissue types or anatomical regions. ROI analysis relies on an individual or automated segmentation to delineate particular structures such as the cingulum bundles (a) or corpus callosum (b). Both methods have limitations and benefits, and should be used with a clear understanding of the assumptions of the methodology whether alone or in combination. 
A
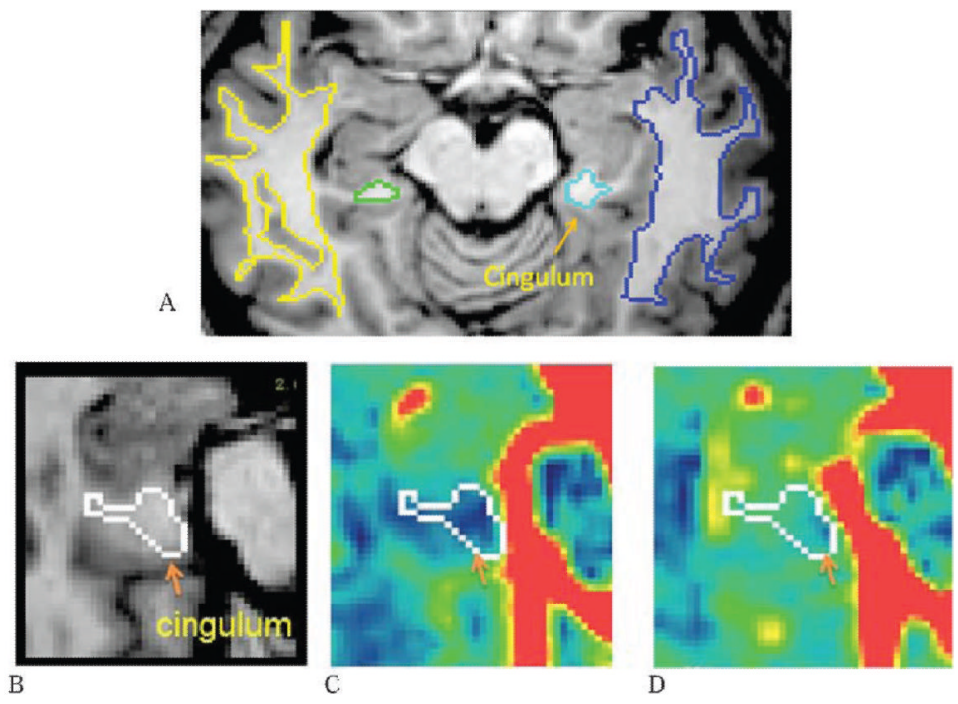

FIG. 2.

Prospective human MR DTI study to assess changes in normal appearing white matter following whole-brain radiation therapy (WBRT). Panel A shows an MR T1-weighted axial slice illustrating the different regions of interest defined for each patient including parahippocampal cingulum outlined in green (right hemisphere) and light blue (left hemisphere). Temporal lobe white matter (yellow and blue) regions are also shown. Panel B shows an MRI T1-weighted MR axial slice obtained at baseline prior to WBRT; the parahippocampal cingulum is outlined in white. In panel C, a calculated MR DTI map of $\lambda_{\perp}$ is shown. Parahippocampal white matter prior to WBRT appears dark on $\lambda_{\perp}$ images indicating greater diffusion in the direction parallel to the white matter fiber tracts. However, 1 month following $30 \mathrm{~Gy}$ WBRT, there is a significant increase in $\lambda_{\perp}$ indicating early demyelination in the region of the parahippocampal cingulum (panel D). 


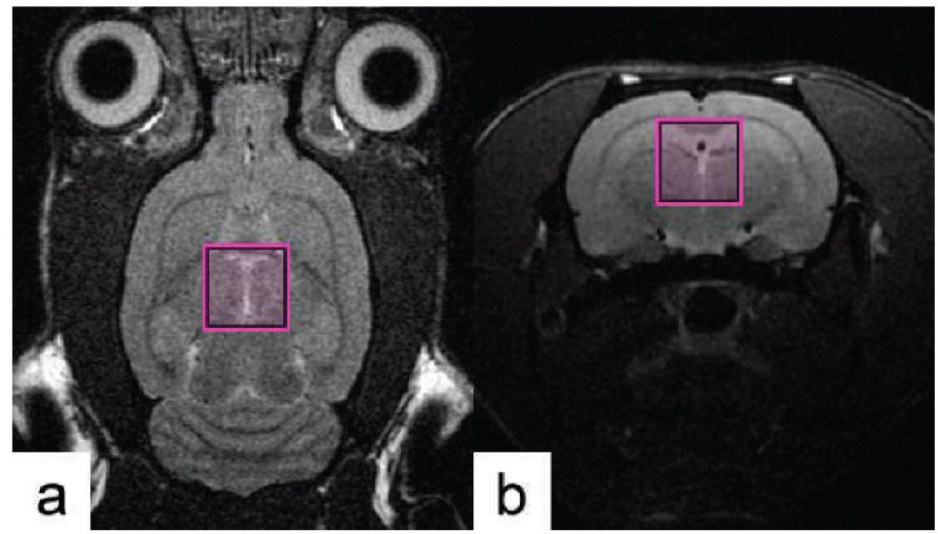

FIG. 3.

High-resolution $\mathrm{T}_{2}$-weighted control (panel a) and axial (panel b) images illustrating the location of the $5 \times 5 \times 5 \mathrm{~mm}$ voxel used to obtain the MR spectra in the fWBI rat brain (79). 


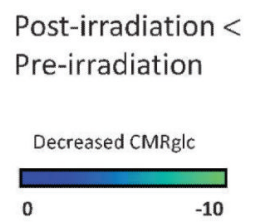

0

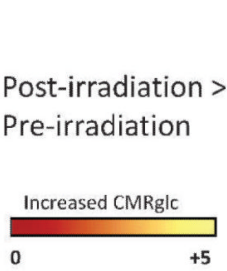

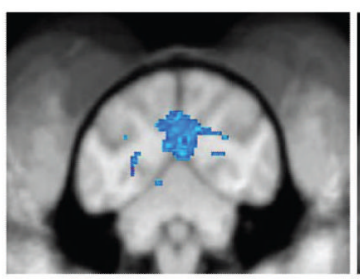

Cuneate Cortex

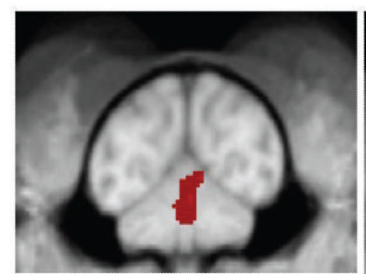

Cerebellum

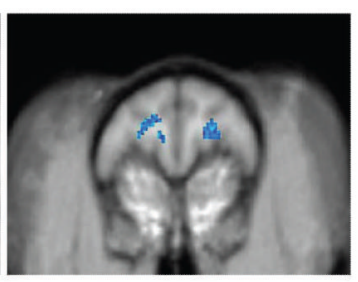

Prefrontal Cortex

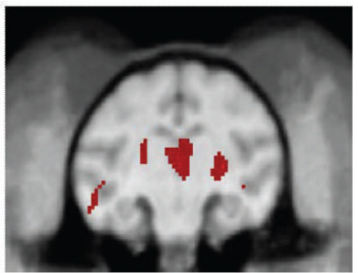

Thalamus

FIG. 4.

$\left[{ }^{18}\right.$ F $]$ FDG-PET scans of cerebral glucose metabolism 9 months after fWBI. Upper panel: post-irradiation < pre-irradiation. Blue areas in the cuneate cortex and prefrontal cortex exhibited less metabolic activity in fWBI scans obtained 9 months after fWBI than in the scans prior to fWBI. Lower panel: post-irradiation > pre-irradiation: The red areas in the cerebellum and thalamus showed greater metabolic activity in the fWBI scans obtained 9 months after fWBI than in the scans prior to fWBI. The color bar is the degree of intensity difference shown as a scale of $\mathrm{t}$ values with $P<0.001(80)$. 
A

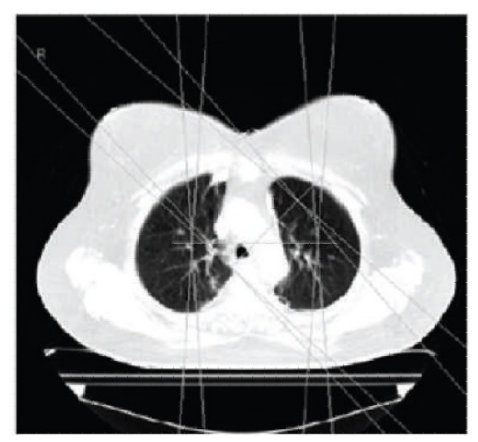

$\mathrm{B}$

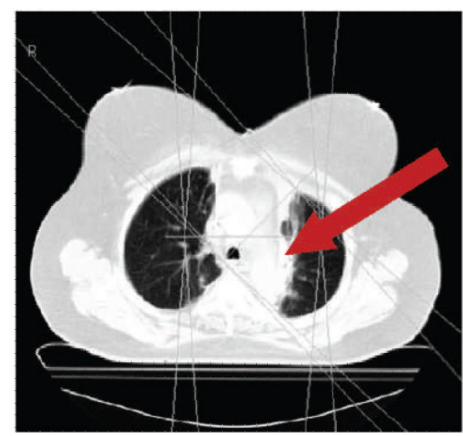

FIG. 5.

Shows the (panel A) pre- and (panel B) 12-month post-radiation therapy (RT) computed tomography images from an irradiated lung cancer patient. The beam paths are shown (anterior, posterior, oblique). The arrow indicates the region of increased CT density in the irradiated medial left lung following RT. [Adapted from Kocak (102) with permission.] 
A

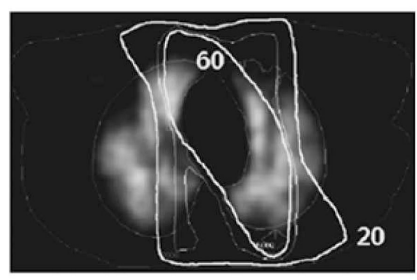

B
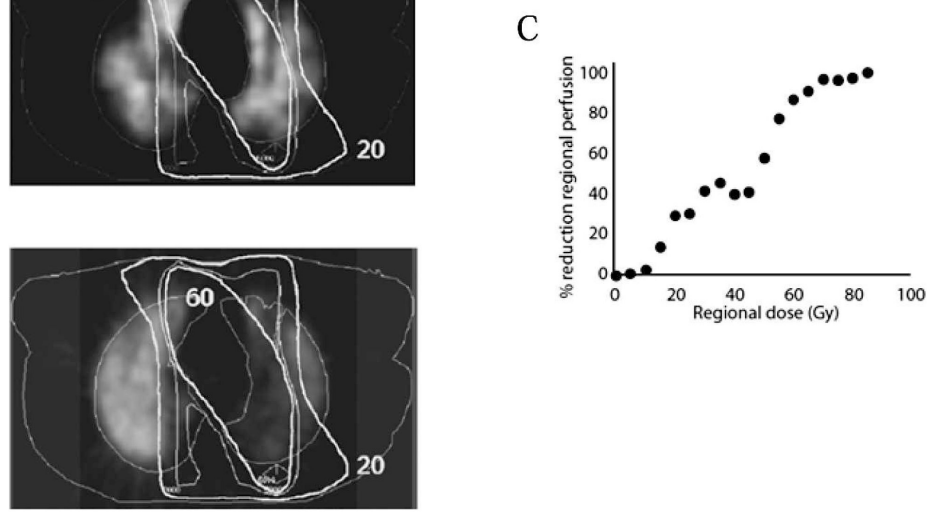

FIG. 6.

Shows the (panel A) pre- and (panel B) 6-month post-radiation therapy (RT) transverse SPECT perfusion images from an irradiated lung cancer patient. The RT dose distribution, relative to isodose contours, is also shown. Panel C shows the dose-response curve for RTinduced reductions in regional perfusion from the patient's SPECT scans; post-RT perfusion defects are seen most predominantly within regions of the lung receiving >60 Gy. [Adapted from Kocak (102) with permission.] 


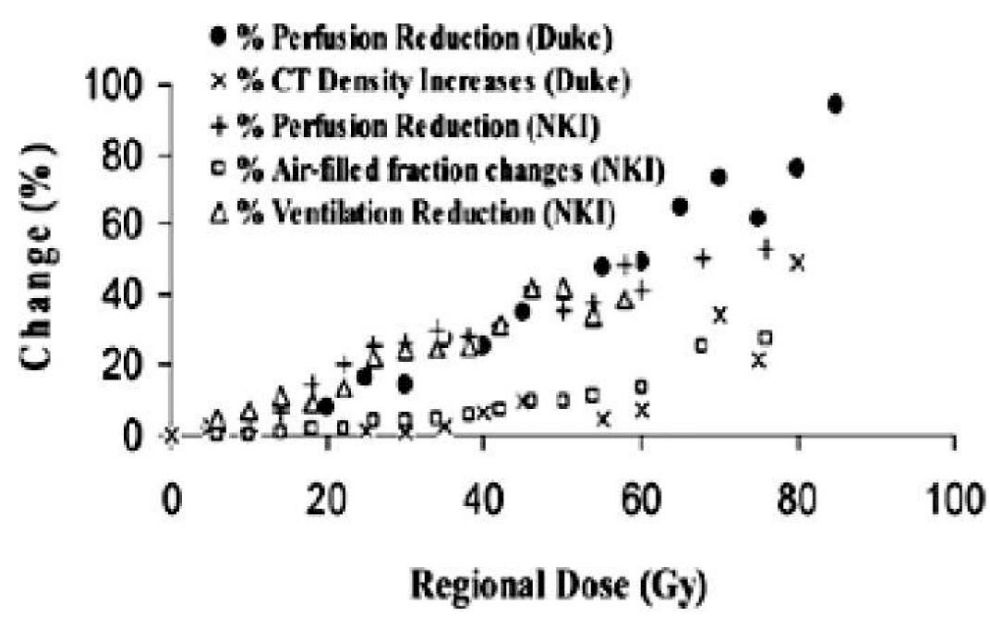

FIG. 7.

Dose-dependent reductions in regional SPECT perfusion and ventilation, as well as increases in CT density in patients receiving lung irradiation. [Adapted from Marks (114) with permission; data from Netherlands Cancer Institute $(109,111,112)$ and Duke $(100$, 113).] 
A

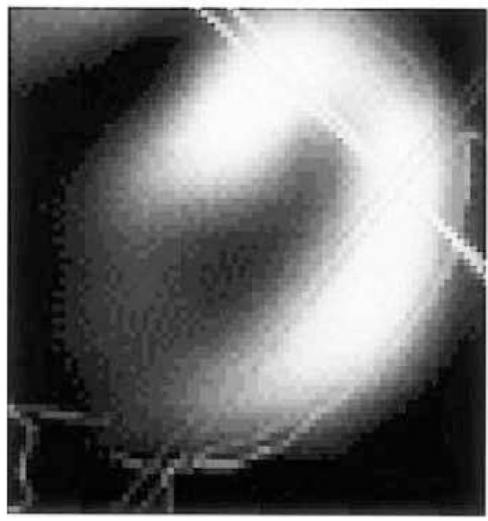

\section{$\mathrm{B}$}

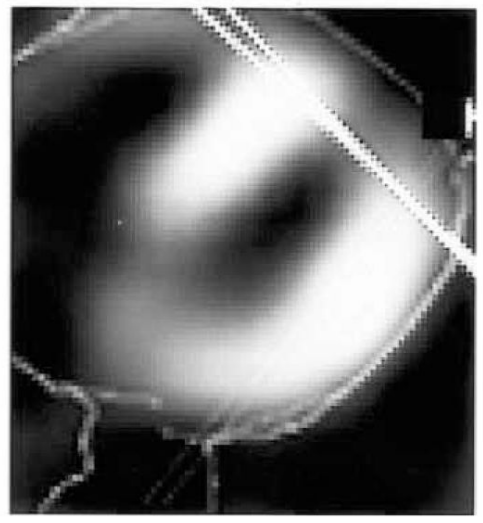

FIG. 8.

Cardiac SPECT scans showing representative axial images obtained (panel A) pre-RT and (panel B) post-RT. The deep tangent border is shown as the solid line. A new perfusion defect after irradiation is seen in the anterior left ventricle. [Adapted from Marks et al. (134) with permission.] 


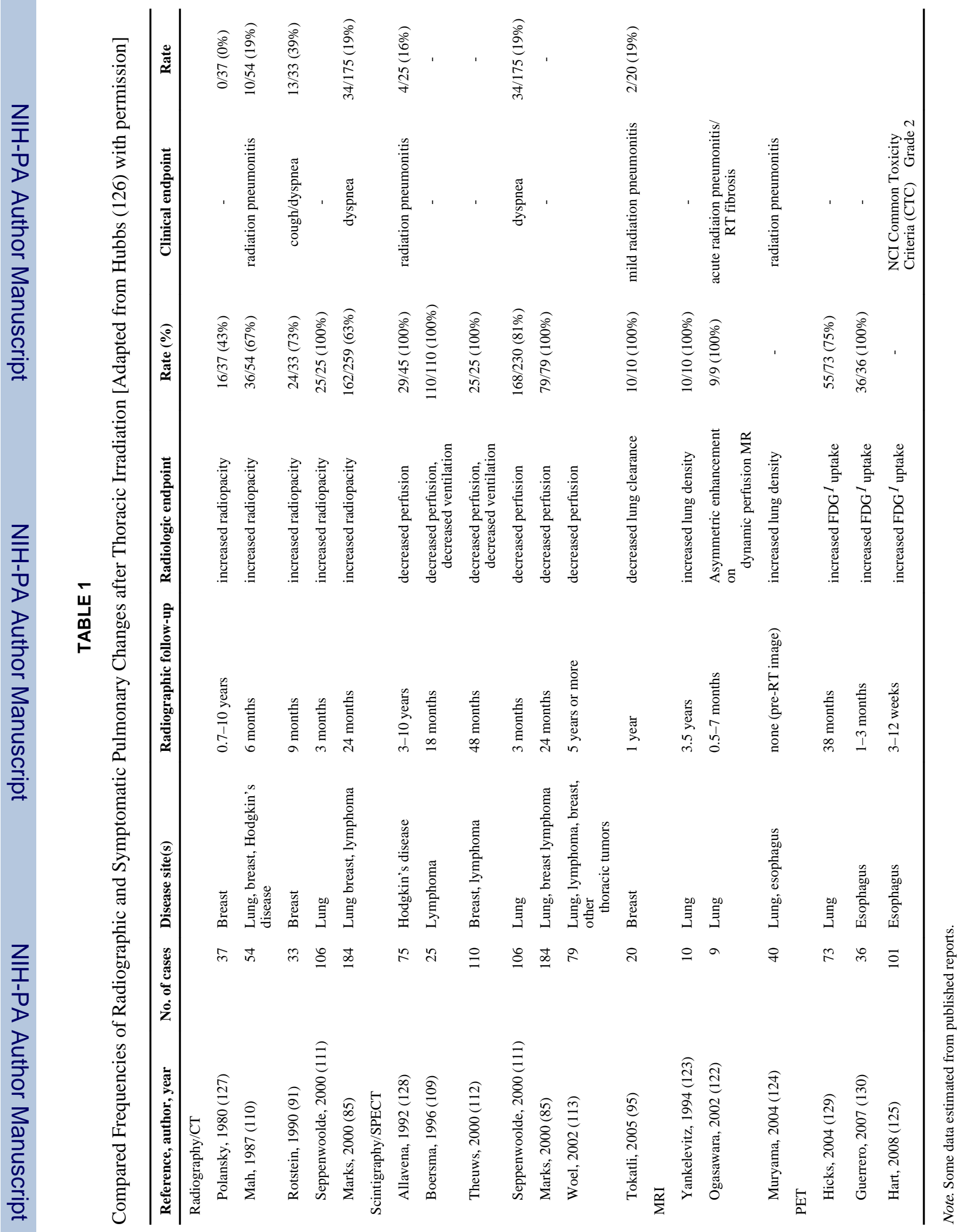


TABLE 2

Compared Frequencies of Radiographic and Symptomatic Cardiac Changes after Thoracic Irradiation [Adapted from Hubbs (126) with permission]

\begin{tabular}{|c|c|c|c|c|c|c|}
\hline Reference, author, year & Years of RT & $\begin{array}{r}\text { No. } \\
\text { of cases }\end{array}$ & $\begin{array}{l}\text { Median radiographic } \\
\text { follow-up }\end{array}$ & Subgroup & perfus & $\begin{array}{r}\text { Rate of } \\
\text { ofects }\end{array}$ \\
\hline \multicolumn{7}{|l|}{ Breast cancer - retrospective } \\
\hline \multirow[t]{2}{*}{ Gyenes, 1994 (140) } & 1971-1976 & 37 & 18.4 years & Left-sided photons or electrons & $25 \%$ & $(5 / 20)$ \\
\hline & & & 19 years & Right-sided photons or electrons & $0 \%$ & $(0 / 17)$ \\
\hline \multirow[t]{2}{*}{ Gustavsson, 1999 (141) } & $1978-1983$ & 90 & 13 years & Left-sided RT & $12 \%$ & $(4 / 34)$ \\
\hline & & & & Right-sided or no RT & $4 \%$ & $(2 / 56)$ \\
\hline \multirow[t]{2}{*}{ Højris, 2000 (142) } & $1982-1990$ & 16 & 7.9 years & Left-sided electrons & $44 \%$ & $(4 / 9)$ \\
\hline & & & & No RT & $57 \%$ & $(4 / 7)$ \\
\hline Cowen, 1998 (143) & 1987-1993 & 17 & 8.4 years & Left-sided photons & $0 \%$ & $(0 / 17)$ \\
\hline \multirow[t]{2}{*}{ Girinsky, 2000 (144) } & $1987-1995$ & 36 & 6.7 years & Left-sided photons & $71 \%$ & $(17 / 24)$ \\
\hline & & & 8.3 years & Right-sided photons & $17 \%$ & $(2 / 12)$ \\
\hline \multicolumn{7}{|l|}{ Breast cancer - prospective } \\
\hline \multirow[t]{2}{*}{ Gyenes, 1996 (136) } & 1993-1994 & 12 & 1.1 year & Left-sided photons & $100 \%$ & $(4 / 4)$ \\
\hline & & & & Left-sided electrons & $25 \%$ & $(2 / 8)$ \\
\hline \multirow[t]{4}{*}{ Marks, 2005 (134) } & 1998-2001 & 114 & 0.5 year & Left-sided photons & $27 \%$ & $(21 / 77)$ \\
\hline & & & 1 year & Left-sided photons & $29 \%$ & $(16 / 55)$ \\
\hline & & & 1.5 years & Left-sided photons & $38 \%$ & $(13 / 34)$ \\
\hline & & & 2 years & Left-sided photons & $42 \%$ & $(11 / 26)$ \\
\hline \multirow[t]{4}{*}{ Prosnitz, 2007 (135) } & 1998-2006 & 44 & 3 years & Left-sided photons & $38 \%$ & $(3 / 8)$ \\
\hline & & & 4 years & Left-sided photons & $58 \%$ & $(7 / 12)$ \\
\hline & & & 5 years & Left-sided photons & $67 \%$ & $(4 / 6)$ \\
\hline & & & 6 years & Left-sided photons & $67 \%$ & $(2 / 3)$ \\
\hline \multicolumn{7}{|l|}{ Other disease sites } \\
\hline Savage, 1990 (145) & $1967-1985$ & 16 & $9.3(2.5-21.5)$ years & Hodgkin's disease & $0 \%$ & $(0 / 16)$ \\
\hline Gustavsson, 1990 (146) & & 26 & $15(4-20)$ years & Hodgkin's disease & $61 \%$ & $(14 / 23)$ \\
\hline Maunoury, 1992 (147) & 1978-1988 & 31 & $7(3-11)$ years & Hodgkin's disease & $84 \%$ & $(21 / 25)$ \\
\hline Glanzmann, 1998 (148) & 1964-1992 & 112 & $11.2(1.0-31.5)$ years & Hodgkin's disease & $7 \%$ & $(7 / 100)$ \\
\hline Girinsky, 2000 (144) & & 49 & 75 (28-208) months & Hodgkin's disease & $78 \%$ & $(32 / 41)$ \\
\hline Heidenreich, 2007 (149) & 1964-1994 & 294 & $6.5(4.0-8.4)$ years & Hodgkin's disease & $12 \%$ & $(32 / 274)$ \\
\hline Gayed, 2006 (150) & $2005-2006$ & 51 & 3 months & Esophageal cancer & $54 \%$ & $(14 / 26)$ \\
\hline Lind, 2006 (151) & & 13 & 2 months, 6 months & Lung cancer & & \\
\hline Hubbs, 2008 (152) & 2006-2007 & 12 & $3,6,12$, and 18 months & Lung cancer, Mesothelioma & $50 \%$ & $(6 / 12)$ \\
\hline
\end{tabular}

Radiat Res. Author manuscript; available in PMC 2013 August 05. 